\title{
Tailoring the Supramolecular Structure of Guanidinylated Pullulan toward Enhanced Genetic Photodynamic Therapy
}

\author{
Jie Zhou,,$^{\dagger}$ Aisha Roshan Mohamed Wali, ${ }^{\prime \prime}$ Shengnan Ma, ${ }^{\dagger}$ Yiyan He, ${ }^{\not *}$ Dong Yue, ${ }^{\dagger}$ James \\ Zhenggui Tang," and Zhongwei Gü*
}

$\dagger$ National Engineering Research Center for Biomaterials, Sichuan University, No. 29,

Wangjiang Road, Chengdu 610065, Sichuan, P. R. China

†College of Materials Science and Engineering, Nanjing Tech University, 30 South Puzhu Road, Nanjing 211816, P. R. China

TSchool of Pharmacy, Faculty of Science and Engineering, University of Wolverhampton, Wulfruna Street, Wolverhampton WV1 1LY, United Kingdom

KEYWORDS: Gene delivery; Peptide dendrons; Guanidination; Uptake mechanism; Genetic photodynamic therapy 


\begin{abstract}
In the progress of designing a gene carrier system, what is urgently needed is a balance of excellent safety and satisfactory efficiency. Herein, a straightforward and versatile synthesis of a cationic guanidine-decorated dendronized pullulan (OGG3P) for efficient genetic photodynamic therapy was proposed. OGG3P was able to block the mobility of DNA from a weight ratio of 2 . However, G3P lacking guanidine residues could not block DNA migration until at a weight ratio of 15 , revealing guanidination could facilitate DNA condensation via specific guanidinium-phosphate interactions. A zeta potential plateau $(\sim+23 \mathrm{mV})$ of OGG3P complexes indicated the nonionic hydrophilic hydroxyl groups in pullulan might neutralize the excessive detrimental cationic charges. There was no obvious cytotoxicity and hemolysis, but also enhancement of transfection efficiency with regard to OGG3P in comparison with that of native G3P in Hela and HEK293T cells. More importantly, we found that the uptake efficiency in Hela cells between OGG3P and G3P complexes was not markedly different. However, guanidination caused changes in uptake pathway and led to macropinocytosis pathway, which may be a crucial reason for improved transfection efficiency. After introducing a therapeutic pKillerRed-mem plasmid, OGG3P complexes achieved significantly enhanced KillerRed protein expression and ROS production under irradiation. ROS-induced cancer cells proliferation suppression was also confirmed. This study highlights the guanidine-decorated dendronized pullulan could emerge as a reliable non-viral gene carrier to specifically deliver therapeutic genes.
\end{abstract}




\section{INTRODUCTION}

Gene therapy, which garners immense interests worldwide over the last few decades, has become a prevalent means to the treatment of hard-to-treat diseases and tumors. Non-viral gene vectors possess many superior characteristics in comparison with viral gene vectors including biocompatibility, low immunogenicity, easy to scale-up production and so on. ${ }^{1-2}$ The cationic polymeric vector is one of the most important carriers for the delivery of negative genes among varied non-viral gene vectors. Numerous cationic polymers including polyethyleneimine, ${ }^{3-5}$ chitosan, polyamidoamine dendrimers, ${ }^{6-7}$ and poly L-lysine, ${ }^{8}$ are known to be efficient non-viral gene carriers. They can interact with negatively charged DNA, and further form positively charged particles. The cationic surface charge of the complexes plays an essential part in the interaction with negatively charged phospholipid head groups or protein domains of target cells. $^{9-11}$ Nevertheless, cationic surface charge mediated toxicity, non-compatibility, and non-specific interactions with blood components limit the use of cationic polymers. Neutralization of the cationic surface charge is a crucial method to address these issues related to the cationic polymers. For example, shielding of the peripheral cationic groups by PEGylation is demonstrated to reduce the toxicity. However, PEGylation may inhibit the transfection efficiency. ${ }^{12}$ Therefore, designing a gene vector with a balance of excellent safety and satisfactory efficiency is very important.

Cationic derivatives of natural polymers hold great potential as suitable gene carriers owing 
to their low immunogenicity, low toxicity, high flexibility, and availability for large-scale synthesis. Pullulan is a famous natural, neutral and linear homopolysaccharide built by maltotriose trimer through $\alpha-1,6$ linkages. It contains nine hydroxyl groups per repeating unit available for chemical modification. These hydroxyl groups allow the introduction of cationic groups in this neutral pullulan. Moreover, the hydrophilic and nonionic $\mathrm{OH}$ groups of pullulan may neutralize the excessive detrimental cationic charges. Hitherto, much more attention has been paid to the exploration of cationic pullulan derivatives for gene delivery. ${ }^{13-14}$ Peptide dendrimers with fascinating features have been studied as gene vectors due to their versatility, precise nanostructure, good biocompatibility, and rich external amino groups. ${ }^{15-18}$ Although the higher generations of peptide dendrimers may lead to higher transfection activities, ${ }^{16}$ the synthetic challenges of higher generations of peptide dendrimers remain obstacles to use. Hence, taking into account the inherent properties of pullulan and peptide dendrimers, we develop a cationic lysine-based dendronized pullulan for gene delivery.

Numerous strategies have been put forward to enhance transfection efficiency of the cationic polymers, such as the introduction of targeting ligand, increasing the ability to escape from the endosome and so on. ${ }^{4,19-20}$ Cellular penetrating peptides (CPPs) are well-known peptides capable of penetrating plasma membranes of mammalian cells. Among them, human immunodeficiency virus transactivator of transcription protein, oligoarginine, penetratin and virion protein 22 are the best-known ones. The most obviously common feature of these CPP structures is the abundant amount of basic amino acids, especially the amount of arginine guanidinium residue. ${ }^{21-22}$ The 
guanidinium residues seem to be the essential ingredients of the CPPs to cross the plasma membrane, which has allowed for the design of a range of guanidinium-bearing analogs. It is established that modifying the primary amine with guanidinium groups could promote the transfection efficiency. ${ }^{23-25}$ Although the exact mechanism of guanidinium-rich polymers improved gene delivery remains unclear, it is suggested that incorporating guanidinium groups to the cationic polymers is a feasible approach to improve transfection efficiency. ${ }^{20,23}$

Keeping all the points in mind, we proposed a straightforward and versatile synthesis of a cationic guanidine-decorated dendronized pullulan, octa-guanidine functionalized generation 3 lysine dendrons-graft-pullulan (OGG3P), in which low generation cationic lysine-based dendrons were covalently attached to the neutral pullulan through copper(I)-catalyzed alkyne-azide cycloaddition. All of the primary amines at the generation 3 lysine dendron periphery were further modified with guanidine groups. The obtained octa-guanidine functionalized generation 3 lysine dendrons-graft-pullulan (OGG3P) is thought to show efficient transfection and maintain low toxicity. Herein, we studied the synthesis of OGG3P and its figures for gene carriers including the physiochemical properties, toxicity, gene transfection, and uptake mechanism. Additionally, a reliable gene delivery system should enable delivery of therapeutic genes. Therefore, a therapeutic plasmid, pKillerRed-mem, was introduced to OGG3P carriers. KillerRed is a genetically encoded red fluorescent phototoxic protein that acts as an intrinsically produced photosensitizer for photodynamic therapy (PDT). ${ }^{26-27}$ The green light-induced production of ROS and their resulting phototoxicity were then investigated. 


\section{EXPERIMENTAL SECTION}

Materials. Mono-propargylamine was from J\&K Scientific Company. HOBT (1-hydroxybenzotriazole), HBTU (2-(1H-benzotriazole-1-yl)-1,1,3,3,-tetramethyluronium hexafluorophosphate) and Boc-L-Lys(Boc)-OH were commercially supplied from GL Biochem Ltd. Pullulan with a molecular weight of $20 \mathrm{kDa}$, SA (vitamin $\mathrm{C}$ sodium salt), $\mathrm{CuSO}_{4} \cdot 5 \mathrm{H}_{2} \mathrm{O}$ (cupric sulfate pentahydrate), TEA (triethylamine), EDTA·2Na (ethylenediaminetetraacetic acid disodium salt), $\mathrm{PPh}_{3}$ (triphenylphosphine), $\mathrm{CBr}_{4}$ (carbon tetrabromide), $\mathrm{NaN}_{3}$ (sodium azide), and TFA (trifluoroacetic acid), as well as DIEA (N, N-diisopropylethylamine) were obtained from Aladdin. Branched polyethyleneimine with a molecular weight of $25 \mathrm{kDa}$, 1-HPC (1H-Pyrazole-1-carboxamidine hydrochloride), amiloride, and genistein were obtained from Sigma-Aldrich. Organic solvents were purified using the standard method before use.

DMEM (Dulbecco's modified Eagle's medium) and FBS (fetal bovine serum) were purchased from Life Technologies Corporation. CCK-8 (Cell Counting Kit 8) was ordered from Dojindo Laboratories. Label IT® tracker $\mathrm{Cy} 5^{\mathrm{TM}}$ was from Mirus. Hela (human cervical adenocarcinoma cells) and Hek293T (human embryonic kidney 293T cells) were from Shanghai Institutes for Biological Sciences. The kits for luciferase assay and BCA protein assay were ordered from Promega and Pierce, respectively. The pKillerRed-mem was commercially available from Evrogen JSC. DCFH-DA was from Beyotime. MilliQ ultrapure water was used for preparing all buffers, which was filtered $(0.22 \mu \mathrm{m})$ before use. 


\section{Preparation of Alkyne-Modified Generation 3 Poly(L-lysine) Dendrons}

(alkyne-G3(Lys)). The alkyne modified generation 3 poly(L-lysine) dendrons were constructed based on the previously reported literature. ${ }^{28}$ Briefly, to get the product of generation 1 (G1), mono-propargylamine (0.50 g, 1.0 equiv), Boc-L-Lys(Boc)-OH (3.46 g, 1.10 equiv), HOBT (1.35 g, 1.10 equiv), $\mathrm{HBTU}$ (3.79 g, 1.10 equiv) and anhydrous $\mathrm{CH}_{2} \mathrm{Cl}_{2}(30.00 \mathrm{~mL})$ were added into a flask under $\mathrm{N}_{2}$ atmosphere. Then DIEA (6.00 mL, 4.00 equiv) was injected slowly followed by stirring in an ice-water bath for 0.5 hours. Then the mixture was warmed to room temperature (RT) and stirred for one day. After evaporating the $\mathrm{CH}_{2} \mathrm{Cl}_{2}$, chloroform was used for dissolving the sticky solid. Then it was washed twice with the saturated $\mathrm{NaHCO}_{3}$ solution, $1 \mathrm{~mol} / \mathrm{L} \mathrm{HCl}$ solution and saturated $\mathrm{NaCl}$ solution, respectively. The anhydrous $\mathrm{MgSO}_{4}$ was used as a drying agent to treat organic layer, followed by concentration. Then the crude product was purified by column chromatography, which used n-hexane/ethyl acetate $(1 / 4, \mathrm{~V} / \mathrm{V})$ as an eluent. The G1(Lys) dendrons with Boc protecting groups was obtained as a white solid in 64\% (2.24 g) yield. Then, to remove Boc protection groups, anhydrous $\mathrm{CH}_{2} \mathrm{Cl}_{2}$ and TFA $(1 / 1, \mathrm{~V} / \mathrm{V})$ were used as the solvents for the G1(Lys) dendrons, and the reaction lasted for 4 hours under the nitrogen atmosphere. After evaporation of the resulting solution under vacuum, the anhydrous ether was used for the precipitation of the crude solid. A white powder was yielded followed by centrifugation to remove the ether. G2 and G3 dendrons were obtained from G1. Similarly, the process of synthesis and purification of $\mathrm{G} 2$ and $\mathrm{G} 3$ was analogous to that of $\mathrm{G} 1$, using $\mathrm{CH}_{2} \mathrm{Cl}_{2} / \mathrm{MeOH}(10 / 1, \mathrm{~V} / \mathrm{V})$ as an eluent. The product was also acquired as a white solid in 57\% (2.35 g) yield. Then, anhydrous 
$\mathrm{CH}_{2} \mathrm{Cl}_{2}$ and TFA (1/1, V/V) were used for dissolving the $\mathrm{G} 3$ dendrons $(2.00 \mathrm{~g}, 1.10 \mathrm{mmol})$ and the reaction lasted for 8 hours to remove Boc protecting groups of amines under the $\mathrm{N}_{2}$ atmosphere. The resulting mixture was evaporated, and the crude solid was treated with anhydrous ether under stirring overnight. A white powder was yielded followed by centrifugation to remove the diethyl ether. The structures of the synthetic compounds were characterized by ${ }^{1} \mathrm{H}-\mathrm{NMR}$ and Mass Spectrum.

Preparation of Azido Functionalized Pullulan (azido-Pullulan). A typical azidation reaction was carried out according to the literature reported. ${ }^{29}$ Firstly, pullulan (1.00 g, 1 equiv), sodium azide (3.20 g, 8 equiv) and distilled DMF (25.00 mL) were added into the flask under $\mathrm{N}_{2}$ atmosphere. The mixture was then heated to $80^{\circ} \mathrm{C}$ to make the solid completely dissolve, and then it was cooled down in an ice bath. Then $\mathrm{PPh}_{3}\left(2.60 \mathrm{~g}, 1.6\right.$ equiv) and $\mathrm{CBr}_{4}(3.28 \mathrm{~g}, 1.6$ equiv) were dissolved respectively in distilled DMF and injected into the above mixture. Following that, the mixture was warmed to RT overnight until the color transformed from orange to brown. In order to quench the reaction, $1.00 \mathrm{~mL}$ of methanol was added. And the pullulan derivatives were precipitated by adding ethanol $(200.00 \mathrm{~mL})$. A white powder was harvested through centrifugation, and then $150.00 \mathrm{~mL}$ mixture of ethanol and water $(7 / 3, \mathrm{~V} / \mathrm{V})$ was used for washing. Finally, it was washed with $100.00 \mathrm{~mL}$ of ethanol. The obtained product was dried in vacuum, and the light brown-colored solid polymer was obtained. The azido group content of azido-pullulan was determined by elemental analysis (EA).

Preparation of G3(Lys) Functionalized Pullulan (G3P). The synthesis of G3(Lys) dendron 
functionalized pullulan (G3P) was achieved by the "click" reaction, the copper-catalyzed azide-alkyne cycloaddition. Azido-pullulan ( $0.17 \mathrm{~g}, 1$ equiv) was dissolved in DMSO under argon atmosphere. Alkyne-G3(Lys) (0.33 g, 2 equiv) and vitamin C sodium salt ( $0.05 \mathrm{~g}, 1.35$ equiv) were dissolved in the deionized water respectively and added into the above solution. Then the $\mathrm{CuSO}_{4} \cdot 5 \mathrm{H}_{2} \mathrm{O}(0.03 \mathrm{~g}, 0.70$ equiv $)$ was also dissolved in deionized water and injected under a constant flow of argon. Then the solution was kept stirring at $45^{\circ} \mathrm{C}$ for two days in the dark. EDTA $2 \mathrm{Na}$ power $(0.04 \mathrm{~g})$ was added into the above solution to chelate the excess copper ion. Finally, the mixture was dialyzed (MWCO: $3500 \mathrm{Da}$ ) with deionized water for two days followed by lyophilization to get the product (G3P).

Preparation of Octa-Guanidine G3P (OGG3P). The octa-guanidine G3P (OGG3P) was prepared by using an attractive guanidinylation reagent, 1H-pyrazole-1-carboxamidine hydrochloride, which produced substituted guanidines from primary amines. The primary amines of G3P were guanidinylated in water with 5 equiv of 1-HPC and DIEA. Having a reaction at RT for one day, the white solid product of OGG3P was gained by dialysis against distilled water for two days using a dialysis membrane (MWCO: $3500 \mathrm{Da}$ ) to remove unbound entities. The structures of G3P and OGG3P were characterized through ${ }^{1} \mathrm{H}-\mathrm{NMR}$ and elemental analysis (EA). The content of guanidines in the OGG3P polymer was also determined by elemental analysis.

DNA Complexes Assembly. The complexes were prepared by mixing DNA with cationic G3P or OGG3P solution gently at different weight ratios from 0.2 to 200 (cationic G3P or OGG3P to DNA) in HBG buffer (HEPES $20 \mathrm{mM}$, pH 7.4, 5\% glucose), and incubating at RT for 0.5 hours 
prior to use.

Agarose Gel Electrophoresis Assay. In order to study the DNA compaction ability of G3P or OGG3P, gel electrophoresis assay was introduced. Various G3P/DNA complexes and OGG3P/DNA complexes with weight ratios from 0.2 to 200 were prepared and let stand at $37^{\circ} \mathrm{C}$ for 0.5 hours. Naked DNA and $25 \mathrm{kDa}$ PEI/DNA complexes at a weight ratio of 1.33 were used as negative and positive controls, respectively. The final amount of DNA was adjusted to $200 \mathrm{ng}$ per well. Ten microliters of each sample were analyzed by $1 \%$ agarose gel electrophoresis $(80 \mathrm{~V}, 45$ min) in standard TAE buffer. After electrophoresis, ethidium bromide was used for staining the gel, and then the resultant DNA migration behaviors were visualized through the Molecular Imager ChemiDoc XRS+ (Bio-Rad, USA).

Size and Zeta Potential Measurements. Complexes at varying weight ratios were prepared with $3 \mu \mathrm{g} / \mathrm{mL}$ DNA for each sample. Malvern Instruments (Zetasizer Nano ZS, Malvern, UK) were conducted to monitor size distribution and zeta potential of complexes in deionized water.

Transmission Electron Microscopy Determination. A drop of the complexes solution $(0.20 \mathrm{mg} / \mathrm{mL})$ was deposited onto a carbon-coated cupper grid. Then the morphologies of G3P and OGG3P complexes at the weight ratio of 8 were examined using transmission electron microscope (Tecnai G2 F20 S-TWIN, FEI).

Cell Culture and Viability Assay. Hela and Hek293T cells were cultivated in Dulbecco's Modified Eagle Medium (high glucose) containing $100 \mu \mathrm{g} / \mathrm{mL}$ streptomycin, $100 \mathrm{IU} / \mathrm{mL}$ penicillin and $10 \%(\mathrm{~V} / \mathrm{V}) \mathrm{FBS}$ in a humidity atmosphere containing $5 \% \mathrm{CO}_{2}$ at $37^{\circ} \mathrm{C}$. 
CCK-8 experiments were performed to study the cytotoxicity of the cationic polymers (G3P and OGG3P) and complexes (G3P/DNA and OGG3P/DNA). Firstly, the Hela and Hek293T cells were seeded at a cell density of 10000 cells/well in the 96 -well culture plate and cultivated overnight so as to get a confluence of $70 \%-80 \%$. The corresponding amount of cationic polymers or complexes were added into the wells. After incubating for another one day, the medium was discarded, and cells were immediately washed twice in phosphate-buffered saline (pH 7.4). Then 100 microliter fresh medium containing 10\% CCK-8 was added to the wells for additional 2 hours of incubation in the dark. The viability was then analyzed with a microplate reader (Model 550, Bio-Rad) and showed as the viable percentage of cells in relative to the control.

Hemolytic Activity Assay. The animal studies were conducted under the guidelines of the ethics committee of Sichuan University. The hemolytic activity of the cationic polymers (OGG3P, G3P, and PEI) was evaluated according to the previous literature. ${ }^{13}$ Briefly, fresh whole blood was collected in heparinized-tubes from BABL/C mice (Dashuo Experimental Animal Company, China), and then red blood cells were harvested through centrifugation at $1500 \mathrm{rpm}$ for five min. After removal of the supernatant, the pellet was washed with cold PBS buffer at 1500 rpm until the supernatant was clear. $200 \mu \mathrm{L}$ diluted red blood cell $(16 \%$, V/V) suspension was added to $800 \mu \mathrm{L}$ of polymer solution with varying concentrations to make the final concentrations from 8 to $60 \mu \mathrm{g} /$ mL. $200 \mu \mathrm{L}$ of diluted red blood cell suspension blended with $800 \mu \mathrm{L}$ of PBS or sterile water was acting as the negative or positive controls, respectively. The specimens were incubated for $90 \mathrm{~min}$ at $37^{\circ} \mathrm{C}$ followed by centrifugation of $1500 \mathrm{rpm}$ for $5 \mathrm{~min} .200 \mu \mathrm{L}$ of supernatant was added to the 
well of the 96-well plate. The absorbance at the wavelength $540 \mathrm{~nm}$ was detected through microplate reader. The percentage of hemolysis was expressed using the following formula: lysis\% $=(A s-A p) /(A n-A p) \times 100 \%$, where As, Ap and An represent the absorbance of samples, positive and negative controls, respectively.

In Vitro Gene Transfection. Gene transfection properties of the OGG3P polymer were estimated in Hela and Hek293T cells using pEGFP and pGL3 plasmids. Firstly, cells were seeded at a density of 10000 cells/well in the 96-well plates and cultivated overnight. Prior to transfection, the wells were refilled with $100 \mu \mathrm{L}$ of fresh medium (without FBS or with $10 \%$ FBS) containing various DNA complexes (200 ng plasmid DNA per well, cationic polymers to DNA weight ratios from 2 to 30 ). After incubating at $37^{\circ} \mathrm{C}$ for additional 4 hours, the medium was exchanged with fresh medium. The transfection efficiencies of the green fluorescent protein were observed by the fluorescence microscope (Leica, Germany) 44 hours later. Meanwhile, the percentage of the GFP-positive cells was also measured using BD Accuri C6 flow cytometry.

As for the expression of luciferase, after removal of the medium 24 hours later, the cells were rinsed twice with cold PBS. Then it was lysed with lysis buffer and placed in the $-80^{\circ} \mathrm{C}$ refrigerator overnight. The luciferase activity and protein content were evaluated by using luciferase assay and BCA protein assay, respectively. Transfection activity was shown as the relative fluorescence intensity per mg protein (RLU/mg protein).

Cellular Internalization of the Complexes by Confocal Laser Scanning Microscope. The Label IT® tracker $\mathrm{Cy} 5^{\mathrm{TM}}$ was applied to label DNA according to the manufacturer's protocol. 
Hela cells were seeded in confocal dishes at a density of 20000 cells/well. One day later, the medium was exchanged with fresh serum-free medium and OGG3P or G3P complexes containing $40 \%$ Cy5-labeled DNA at the weight ratio of 8 were added into the dishes at the DNA concentration of $300 \mathrm{ng} /$ well. After 4 hours of cultivation, the dishes were refilled with fresh medium, and cells were cultivated for additional 3 hours. After that, cells were rinsed thrice with cold PBS including $20 \mathrm{U} / \mathrm{mL}$ of heparin sodium to get rid of the complexes bound on the cell surface. The intracellular distribution of Cy5-labeled plasmid transfected by the OGG3P, G3P and PEI complexes was observed by the confocal laser scanning microscope (CLSM, Leica TCS SP5).

Cellular Uptake of the Complexes by Flow Cytometer. Hela cell line was seeded at a density of $8 \times 10^{5}$ cells/well in the 6 -well plate and cultivated overnight. The medium was removed and exchanged with serum-free medium, and different DNA complexes including $1 \mu \mathrm{g}$ Cy5-labeled DNA were used to transfect cells. 4 hours later, the wells were refilled with the fresh complete medium for another 3 hours of cultivation. Then the cells were rinsed thrice with cold PBS containing $20 \mathrm{U} / \mathrm{mL}$ of heparin sodium, harvested and suspended in $0.3 \mathrm{~mL}$ cold PBS. The Cy5 fluorescence intensity (Excitation: 633 nm, Emission: $670 \mathrm{~nm}$ ) was measured with BD Accuri C6 flow cytometer.

Treatments with Endocytosis Inhibitors. Hela cell line was seeded at the density of $8 \times 10^{5}$ cells/well in the 6-well plate to study effects of several inhibitors on the uptake pattern of the tested gene complexes. After incubation for 24 hours to reach a confluence of $70 \%-80 \%$, cells were firstly treated with genistein $(200 \mu \mathrm{M})$ or chlorpromazine $(10 \mu \mathrm{g} / \mathrm{mL})$ for 1 hour, or amiloride $(5$ 
$\mathrm{mM}$ ) for 0.5 hours before adding gene complexes. Genistein is famous for inhibiting caveolae-mediated endocytosis. Chlorpromazine is used for blockade of clathrin-mediated endocytosis, and amiloride is famous for the inhibition of macropinocytosis. Then the cells were transfected with OGG3P and G3P complexes containing $1 \mu \mathrm{g}$ Cy5-labeled pGL3-Luc per well. 4 hours later, the fresh complete medium was used to refill the well for another 3 hours of cultivation. Then the cells were rinsed thrice with cold PBS, harvested and suspended in PBS. The fluorescence intensity of Cy5 was determined through BD Accuri C6 flow cytometer, and the results were analyzed with corresponding software. All of the complexes were prepared at their respective optimal weight ratios. Cells treated with OGG3P or G3P complexes but without any pretreatment of inhibitors were used as controls. The mean fluorescence intensity was expressed as a percent of the fluorescence tested in the absence of inhibitors.

Photoactivation of KillerRed and ROS Production. pKillerRed-mem was introduced to study the effects of cancer therapy. KillerRed protein, a dimeric red fluorescent protein, has fluorescence excitation/emission maxima at 585/610 nm. It could produce ROS when exposed to the green light irradiation. ${ }^{30}$ Hela cells were seeded at the density of 50000 cells/well in the 24-well plate and cultivated overnight. The cells were then treated with OGG3P/pKillerRed-mem complexes at a weight ratio of 8 in serum-free medium. The wells were refilled with fresh complete medium 4 hours later, and cells were cultivated for extra one day to get transgene expression of the KillerRed protein in the dark. In order to detect the produced ROS after green light irradiation, the transfected cells were treated with DCFH-DA, which was a green fluorescent 
probe. And then, the transfected cells were further exposed to the green light $\left(532 \mathrm{~nm}, 4 \mathrm{~W} / \mathrm{cm}^{2}\right)$ for different durations $(0,0.5,1,2,5$, or $10 \mathrm{~min})$ and stained with DAPI to label the nuclear followed by the observation of fluorescence microscope. Meanwhile, the fluorescence intensity of the generated ROS in the transfected cells treated with DCFH-DA after different light exposure was also analyzed through flow cytometer, while cells without any treatment were regarded as a control.

Proliferation Suppression Assay following Intracellular pKillerRed-mem Activation. To explore the proliferation suppression influences on Hela cells following intracellular pKillerRed-mem activation, experiments were performed using Hela cells at a density of 10000 cells/well in the 96-well plate, and cells were cultivated overnight to reach an optimal confluence. Then cells were transfected with different complexes of pKillerRed-mem (PEI, G3P, and OGG3P) at their optimized weight ratios in complete medium or serum-free medium. And then wells were refilled with the fresh complete medium after 4 hours, and cells were cultivated for another one day to get transgene expression in the dark. The plates were exposed to green light (532 nm, 4 $\mathrm{W} / \mathrm{cm}^{2}$ ) for $2 \mathrm{~min}$ and cultivated for additional 1 hour at $37^{\circ} \mathrm{C}$ in the dark. After removal of the culture medium, cells were rinsed twice with PBS. Then 100 microlitre medium including 10\% CCK-8 was added to the wells to maintain additional 2 hours of incubation in the dark. Then the UV absorbance of the product was measured at $450 \mathrm{~nm}$ by the microplate reader (Model 550, Bio-Rad, USA). The proliferation suppression was calculated as the viable percentage of cells treated in relative to the control without light exposure. 
Statistical Analysis. Data are shown as average value \pm standard deviation (SD), acquired from triplicates of $n=6$ independent specimen. Two-way analysis of variance (ANOVA) was used for the statistical differences between treatments groups, and $P$ values $\leq 0.05$ were regarded as statistically significant.

\section{RESULTS AND DISCUSSION}

\section{Characterization of G3(Lys) Functionalized Pullulan (G3P) and Octa-Guanidine G3P}

(OGG3P). We synthesized G3P and OGG3P according to the synthetic route illustrated in Figure 1. We successfully obtained G3(Lys) dendrons functionalized pullulan (G3P) through copper-catalyzed azide-alkyne cycloaddition by conjugating azido functionalized pullulan (azido-pullulan) and alkyne modified G3(Lys) dendrons. The G3P was subsequently subjected to guanidinylation by using an attractive guanidinylation reagent, 1-HPC, which produced substituted guanidines from primary amines and provided the desired octa-guanidine G3P (OGG3P).

Firstly, the synthesis of alkyne-modified G3(Lys) dendrons included two successive condensation of Boc-Lys(Boc)-OH into mono-propargylamine and the removal of Boc groups (Figure 1A). The synthesized alkyne-G1(Lys), alkyne-G2(Lys) and alkyne-G3(Lys) were demonstrated by mass spectrometry (Figure 2). For alkyne-G1(Lys) dendron $(\mathrm{M}=183.24)$, the signal at m/z 184.07 was appointed to $[\mathrm{M}+\mathrm{H}]^{+}$, which suggested that Boc-Lys(Boc)-OH was successfully conjugated to the mono-propargylamine and the removal of Boc groups were 
complete. Meanwhile, concerning alkyne-G2(Lys) $(\mathrm{M}=439.54)$, the signal at $\mathrm{m} / \mathrm{z} 440.18$ was regarded as the $[\mathrm{M}+\mathrm{H}]^{+}$peak. And the mass spectrum of $[\mathrm{M}+3 \mathrm{H}]^{+++}(\mathrm{m} / \mathrm{z}=318.24)$ was assigned to the peak of alkyne-G3(Lys) dendron, implying alkyne-G3(Lys) dendron bearing eight free primary amines had been successfully synthesized.

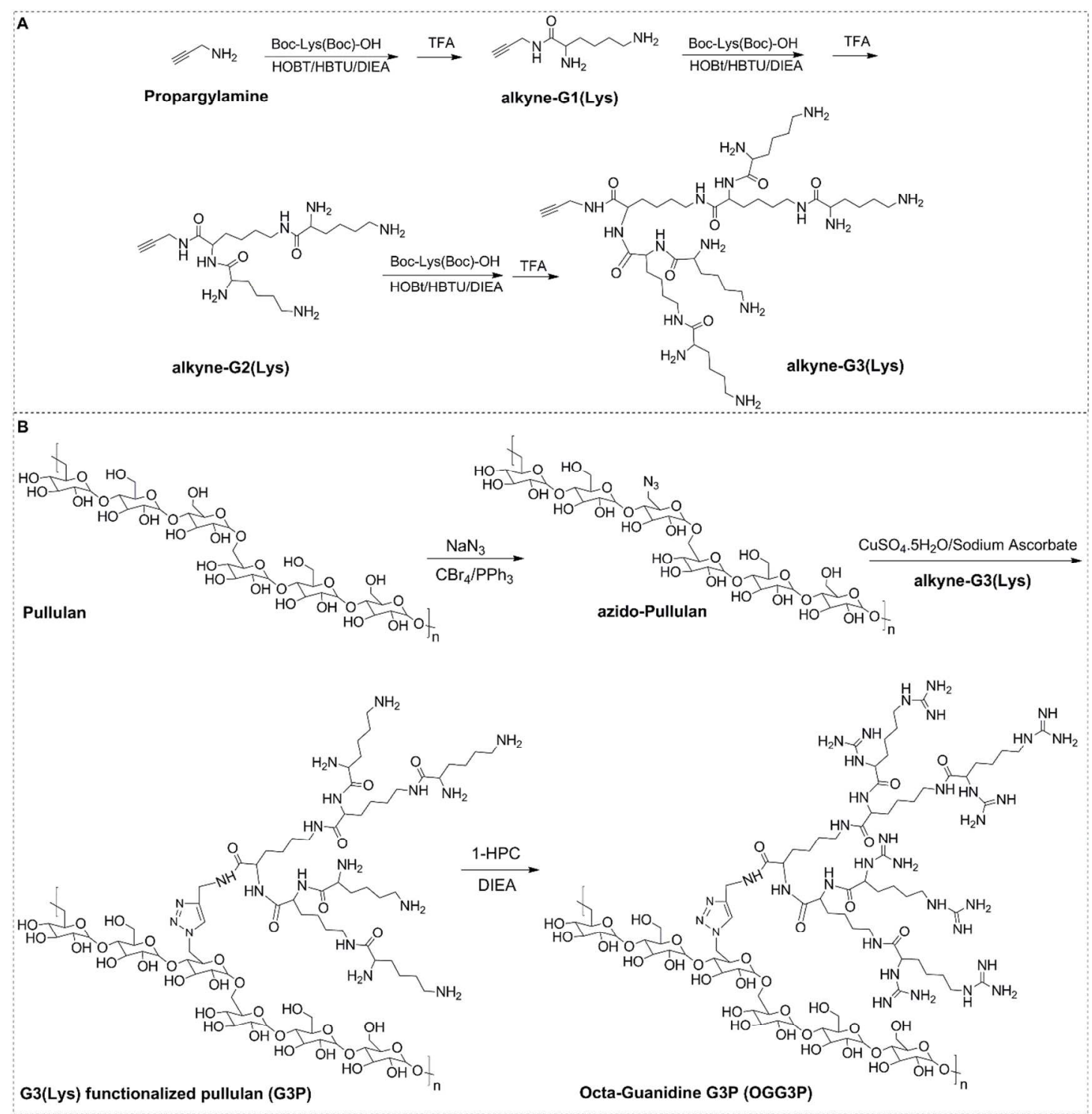

Figure 1. (A) Schematic illustration of the preparation of alkyne-modified generation 3 poly(L-lysine) dendrons (Alkyne-G3(Lys)). (B) Illustration of synthesis procedure of G3(Lys) 
functionalized pullulan (G3P) and octa-guanidine G3P (OGG3P).
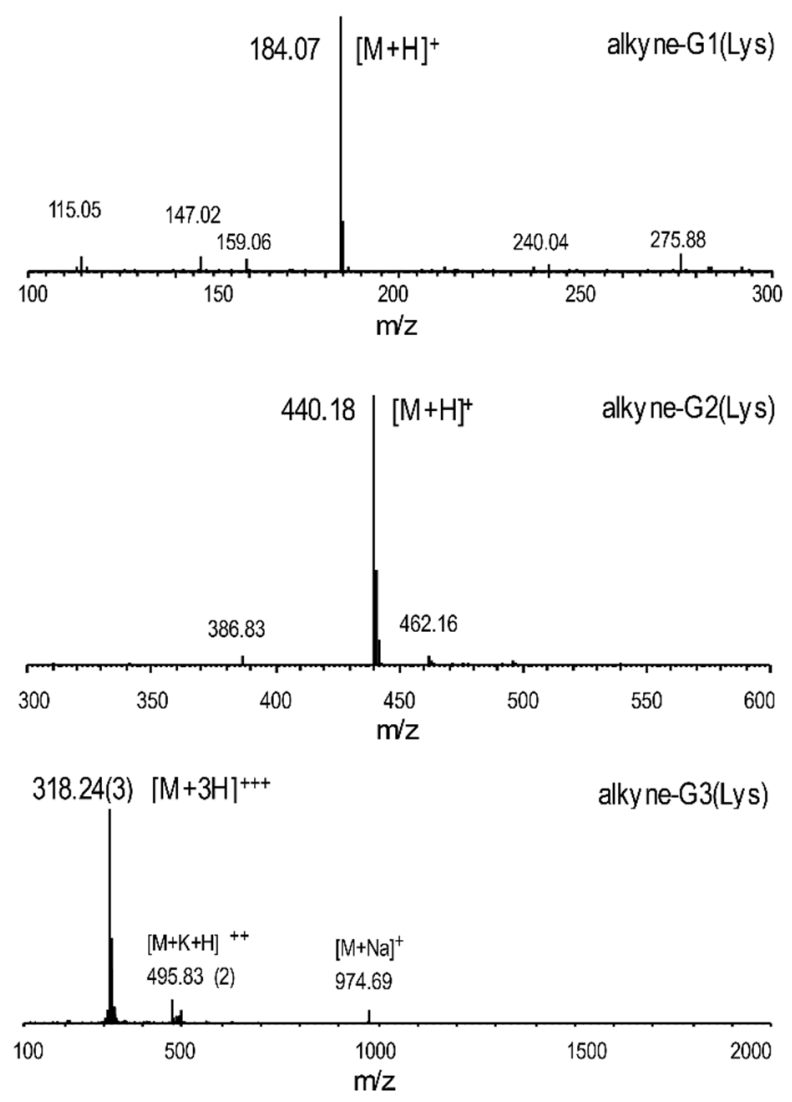

Figure 2. The ESI mass spectra of alkyne-G1(Lys), alkyne-G2(Lys) and alkyne-G3(Lys).

Secondly, the azido groups were introduced to pullulan by one-pot, one-step way (Figure 1B). The G3P was built by the azido groups of azido-pullulan and the alkyne groups of alkyne-G3(Lys) through the azide-alkyne click reaction. The desired OGG3P was generated from the guanidinylation of primary amines in G3P. According to the ${ }^{1} \mathrm{H}-\mathrm{NMR}$ spectra (Figure 3), there were new peaks appeared at 1.0-2.0 ppm and 7.0-8.0 ppm, which could be the signal of alkyne G3(Lys) dendrons. Additionally, the peak at $7.90 \mathrm{ppm}$ was speculated to be the peak of triazole 
proton (proton $c$ ) which was formed from the conjugation of alkyne G3(Lys) dendrons onto azido-pullulan. The primary amines in G3P can be substituted by guanidines using guanidinylation reagent, 1-HPC, ${ }^{31}$ in the aqueous solution. ${ }^{1} \mathrm{H}-\mathrm{NMR}$ spectra also showed the signal intensity of protons near primary amines (proton $b, \delta=3.02$ ) diminished heavily, meanwhile shifted to downfield (proton $f, \delta=3.18$, guanidine groups nearby protons). Therefore, data from ${ }^{1} \mathrm{H}-\mathrm{NMR}$ spectra proved that we have successfully synthesized both G3P and OGG3P. At the same time, the comparison of integration values between the two proton peaks ( $b$ and $f$ ) also revealed that about $95.90 \%$ of primary amines in the G3P polymer were converted to guanidines.

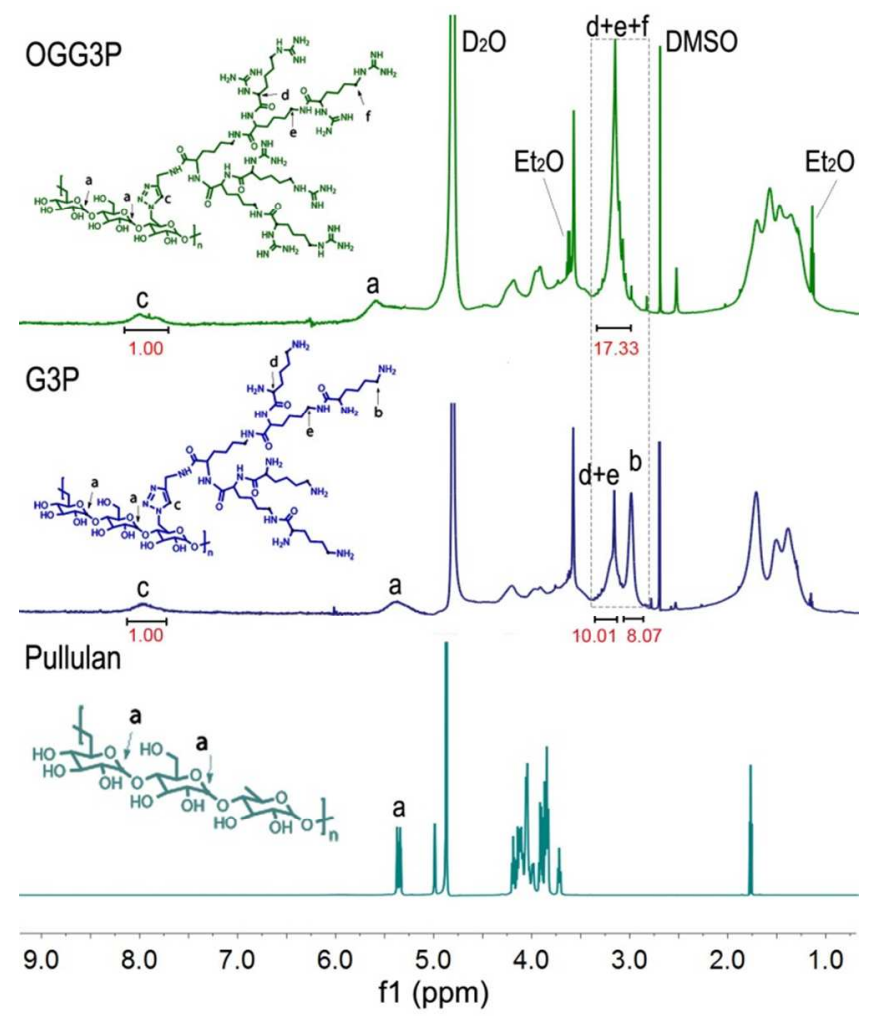

Figure 3. The ${ }^{1} \mathrm{H}-\mathrm{NMR}$ spectra of pullulan, G3(Lys) functionalized pullulan (G3P) and octa-guanidine $\mathrm{G} 3 \mathrm{P}$ (OGG3P), in $\mathrm{D}_{2} \mathrm{O}$. 
In order to further calculate the content of azido group and alkyne G3(Lys) dendrons conjugated onto pullulan, elemental analysis was carried out. Table 1 presented the accurate mass measurements of pure pullulan, azido-pullulan, G3P and OGG3P. The azido content of azido-pullulan was calculated to be 49.02 per 100 anhydrous glucoside units. And the alkyne G3(Lys) dendrons contents conjugated onto pullulan was determined as 12.62 per 100 anhydrous glucoside units, whereas the contents of guanidines modified alkyne G3(Lys) dendrons in OGG3P were 12.52 per 100 anhydrous glucoside units. The elemental analysis further confirmed that the substitution degree of guanidinylated G3P was confirmed to be $99.21 \%$, which was in line with the guanidinylation degree determined from ${ }^{1} \mathrm{H}-\mathrm{NMR}$. In other words, almost all primary amines in G3(Lys) of OGG3P cationic polymer were transformed to guanidines.

Table 1. The substitution degree analyzed by elemental analysis.

\begin{tabular}{ccccc}
\hline & $\mathrm{C}(\%)$ & $\mathrm{H}(\%)$ & $\mathrm{N}(\%)$ & $\mathrm{DS}(\%)$ \\
\hline $\begin{array}{c}\text { Pullulan } \\
\text { Azido- }\end{array}$ & 40.33 & 6.66 & $/$ & $/$ \\
$\begin{array}{c}\text { Pullulan } \\
\text { G3P }\end{array}$ & 37.11 & 6.56 & 3.74 & 49.02 \\
OGG3P & 39.24 & 6.59 & 11.56 & 12.62 \\
\hline
\end{tabular}

Characterization of DNA Complexes. Concerning gene carriers, it is important that the gene carriers are capable of interacting and condensing the plasmid DNA into nanoscale 
complexes and exhibit appropriate positive surface charges. The positively charged nanoscale complexes are apt to interact with the negatively charged cell membrane, presumably facilitating their cellular uptake. ${ }^{11}$ With this in mind, we investigated the DNA compaction ability of the cationic polymers (G3P and OGG3P) using gel retardation assay. DNA and PEI were served as negative and positive controls, respectively. OGG3P was able to fully block the mobility of DNA on the gel at the weight ratio less than or equal to 2 and form stable complexes with DNA, whereas G3P could not retard the DNA migration until the weight ratio greater than or equal to 15 in Figure 4A. These phenomena strongly suggested that the guanidinylated OGG3P cationic polymer had a better DNA compaction ability than pristine G3P cationic polymer, which may be the result of specific guanidinium-phosphate interactions.

We also investigated the surface charges of OGG3P complexes as a function of OGG3P cationic polymer to DNA weight ratios by measuring the zeta potential of a suspension using a Malvern Nano ZS equipment. When the weight ratio was 1, the zeta potential of OGG3P complexes was $11.73 \mathrm{mV}$ (Figure 4B). Then the zeta potential would increase with the increasing of the OGG3P to DNA weight ratios. A zeta potential plateau $(\sim+23 \mathrm{mV})$ occurred when the weight ratio reached to 6 despite increasing with the weight ratio up to 40, indicating the OGG3P cationic polymers were capable of condensing DNA, and positively charged nanoparticles were formed. In addition, plentiful hydrophilic and nonionic $\mathrm{OH}$ groups in pullulan may neutralize the excessive detrimental cationic charges of the OGG3P cationic carriers. Moreover, the zeta potential of the nanoparticles is most often used as an indicator of dispersion stability. In order to 
realize a reasonably stable dispersion, a zeta potential of about $\pm 25 \mathrm{mV}$ is commonly needed. Therefore, OGG3P complexes solution could disperse stably when the weight ratio was greater than or equal to 6 .

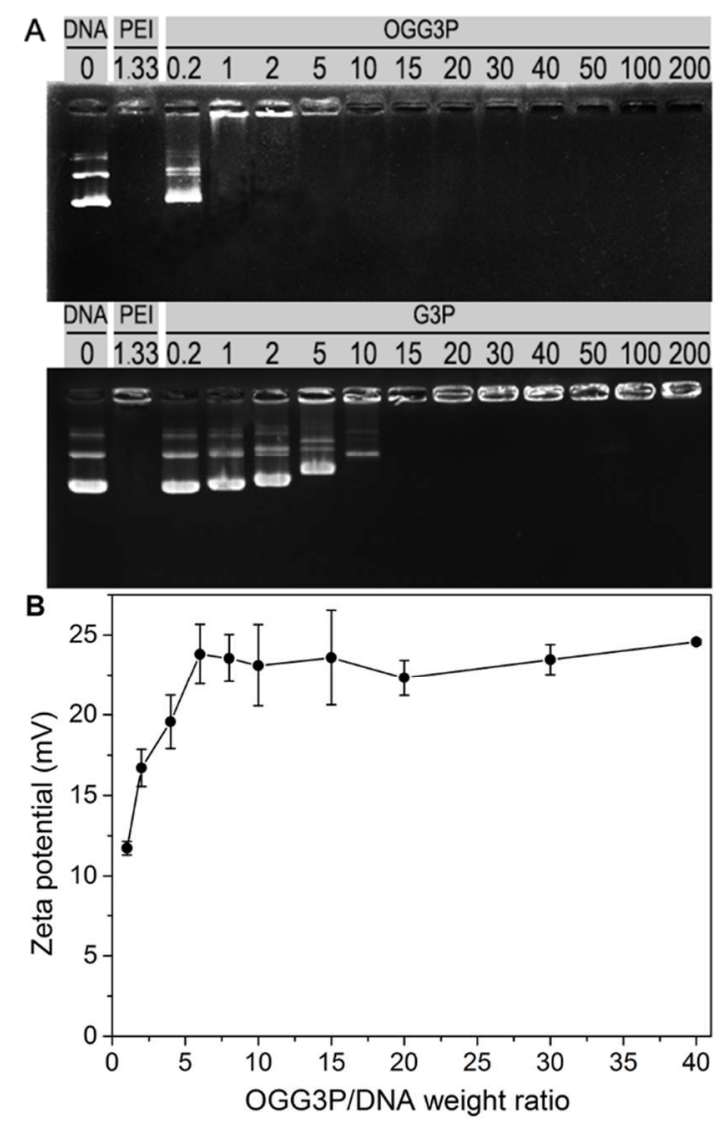

Figure 4. (A) Gel retardation assay for OGG3P and G3P complexes prepared at varying weight ratios. (B) Zeta potential of OGG3P complexes prepared at different OGG3P to DNA weight ratios.

The sizes, size distributions and morphologies of OGG3P and G3P complexes were also monitored by using TEM and dynamic light scattering (DLS). OGG3P and G3P complexes with cationic polymers to DNA weight ratio of 8 were selected. As Figure 5A and 5B shown, results 
from TEM confirmed that both OGG3P and G3P cationic polymers could condense DNA at the weight ratio of 8 and form uniform, compact, and spherical nanoparticles. Samples of OGG3P complexes gave smaller size and narrower size distribution than that of G3P complexes. Additional DLS analyses and zeta-potential measurements also revealed that the resulting OGG3P complexes were well dispersed in the aqueous solution with a size average of $86.1 \pm 6.8 \mathrm{~nm}$ (polydispersity index (PDi): 0.178 ) and present a strong zeta potential of $23.6 \pm 1.5 \mathrm{mV}$. While G3P complexes were $115.2 \pm 10.7 \mathrm{~nm}$ with a wide particle size distribution (PDi: 0.301) and showed a zeta potential of $14.1 \pm 1.3 \mathrm{mV}$ (Figure 5C). As expected, the general trends in sizes and size distributions found from the TEM observation correlated well with those measured by DLS. The above observations indicated the resulting OGG3P complexes possessed a proper size and narrow size distribution, appropriate positive surface charges and good dispersion stability in an aqueous solution, presumably arising from guanidinylated OGG3P had a better DNA compaction ability than pristine G3P cationic polymer. OGG3P cationic polymers with better DNA compaction ability can protect entrapped nucleic acids from nuclease attack and thus ensure their stability and integrity before entering cells. Moreover, the positively charged OGG3P complexes are apt to interact with the negatively charged cell membranes, presumably facilitating their cellular uptake. 

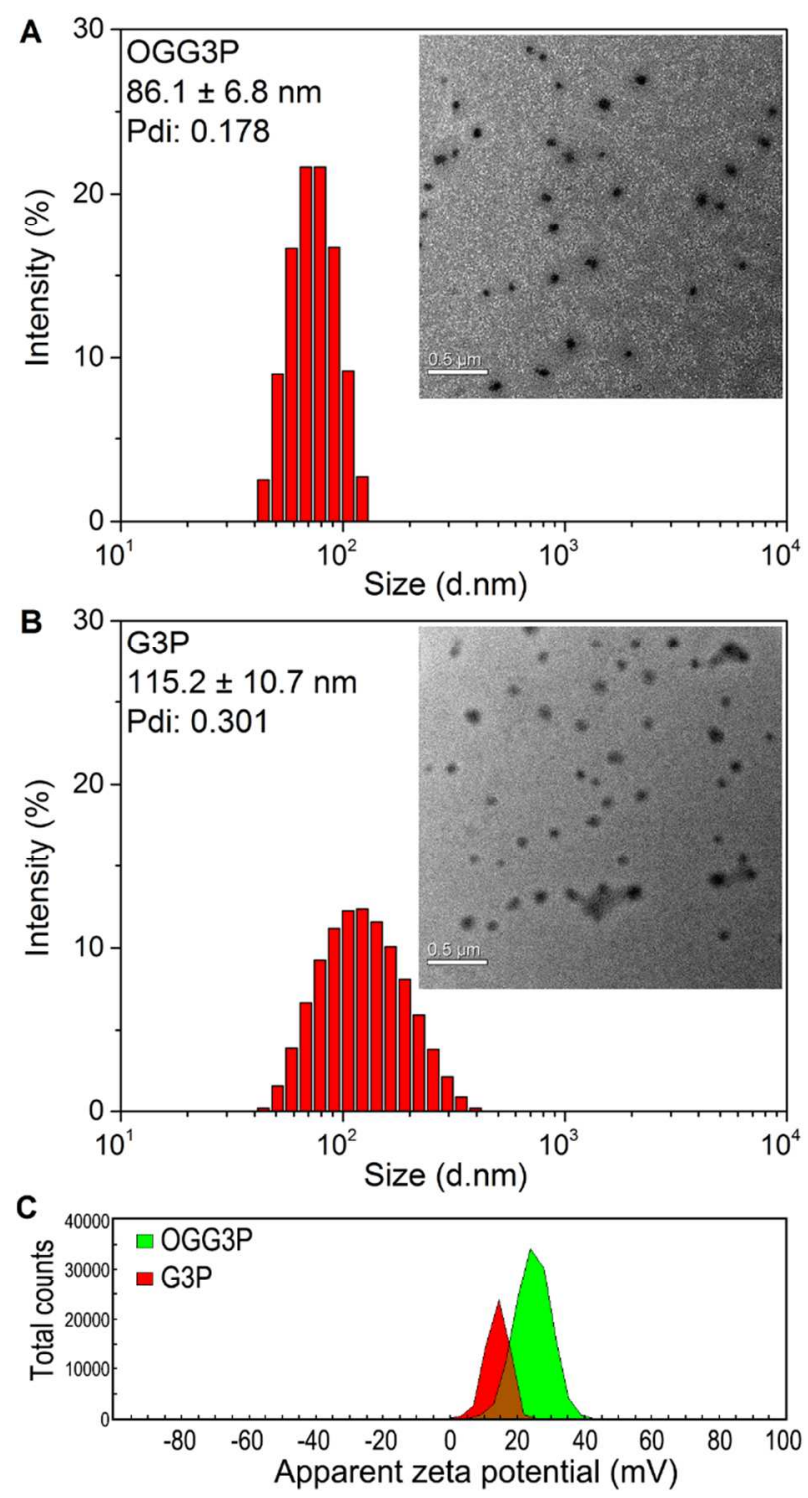

Figure 5. Size distribution and TEM images of (A) OGG3P complexes and (B) G3P complexes at the weight ratio of 8. (C) Zeta potential measurements of OGG3P complexes and G3P complexes.

Biocompatibility of the OGG3P Cationic Polymer. The in vitro biocompatibility of cationic polymers was evaluated by cytotoxicity assay and the absence of serum hemolysis assay. The cytotoxicity of both OGG3P and G3P cationic polymers with different concentration was 
investigated by measuring the cell viability against HEK293T and Hela cell lines, PEI and untreated cells were used as controls. The cell viabilities in Figure 6A and 6B clearly showed that the OGG3P, G3P and PEI cationic polymers induced concentration-dependent cytotoxicity behavior in both HEK293T and Hela cells. As compared to PEI, both OGG3P and G3P showed much higher cell viabilities at the same concentration in both cell lines. For example, after incubation for 24 hours, cell viabilities of both OGG3P and G3P against HEK293T cell lines were above $80 \%$, although the concentration of cationic polymers was $20 \mu \mathrm{g} / \mathrm{mL}$. As for branched 25 $\mathrm{kDa} \mathrm{PEI}$, the cell viability decreased to nearly $23 \%$ at the same concentration (Figure $6 \mathrm{~A}$ ). Therefore, both OGG3P and G3P cationic polymers showed low cytotoxicity compared with PEI, which corresponded to previous results.

To further validate whether the OGG3P and G3P complexes as gene delivery systems could present excellent biocompatibility against cells, we also evaluated the cytotoxicity of OGG3P and G3P complexes against HEK293T and Hela cells. PEI complexes were acted as the control, and DNA concentration was fixed at $2 \mu \mathrm{g} / \mathrm{mL}$. As expected, a similar result was obtained for the complexes with different weight ratios in Figure 6C and 6D. The viabilities of both OGG3P and G3P complexes slightly decreased as the cationic polymers to DNA weight ratios increased, whereas for PEI complexes, the viability decreased sharply to $28.7 \%$ against HEK293T cells at the weight ratio of 10 (Figure 6C).

As the literature reported, the cationic polymer could lead to the serious side effects on the cell membrane and extracellular matrix proteins. ${ }^{32}$ This phenomenon maybe was resulted from the 
guanidine group of OGG3P, which would lead to the formation of bidentate hydrogen bond between guanidine and cell membrane. It was noteworthy that the cell viability of OGG3P was higher in HEK293T cells than that in Hela cells. This phenomenon may be relevant to arginine residues in the degradation fragment of OGG3P, owing to their growth inhibition and tumor cell death promotion in Hela cells. Although the mechanism is not absolutely comprehended, it has been reported in previous studies..$^{3}$
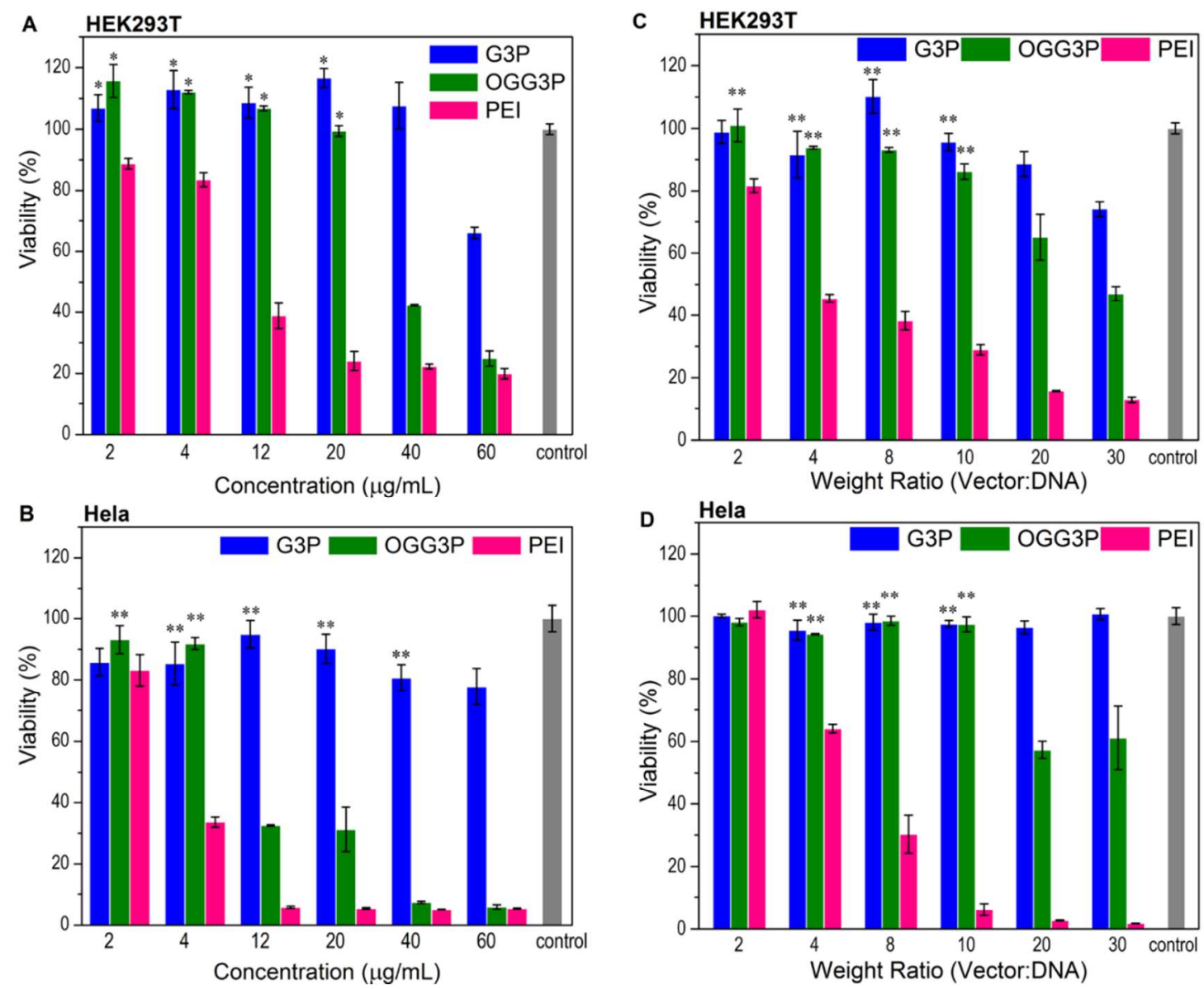

Figure 6. In vitro cytotoxicity of $25 \mathrm{kD}$ branched PEI, OGG3P and G3P cationic polymers against (A) HEK293T cells and (B) Hela cells with different concentrations from 2 to $60 \mu \mathrm{g} / \mathrm{mL}$. In vitro cytotoxicity of PEI, OGG3P and G3P complexes against (C) HEK293T cells and (D) Hela cells at 
varying weight ratios from 2 to 30 , the corresponding DNA concentration was fixed at $2 \mu \mathrm{g} / \mathrm{mL}$. Cells without any treatment were served as positive control and regarded as $100 \%$ viability. $(n=6$, $\left.{ }^{*} p<0.05, * * p<0.01\right)$

\section{Hemolytic Property of the OGG3P Cationic Polymer. The above experimental results} demonstrated that the OGG3P cationic polymer displayed lower cytotoxicity in comparison to that of PEI. It is to mention that when the cationic polymers are injected into the blood for drug or gene delivery, a detrimental interaction of these cationic polymers with blood constituents must be avoided. In view of this, the blood compatibility of OGG3P and G3P cationic polymers was further evaluated by measuring their hemolysis activity. Figure 7 presented the results of hemolysis assays for the cationic polymers at different concentrations. Water and PBS buffer were served as the positive control and negative control, respectively. Measuring the absorbance of the supernatant at $540 \mathrm{~nm}$ could quantitatively determine the released hemoglobin from red blood cells (Figure 7A). Although the concentration was at $60 \mu \mathrm{g} / \mathrm{mL}$, the highest concentration we used in the experiment, as low as $1.78 \%, 1.52 \%$ and $1.88 \%$ of the total hemoglobin were detected for OGG3P, G3P, and PEI, respectively. The hemolytic activities were below the recommended limit of 5\%. Meanwhile, no obvious hemolytic effect can be found even the concentration was $60 \mu \mathrm{g} / \mathrm{mL}$ (Figure $7 \mathrm{~B}$ and 7C). This phenomenon indicated that there was no significant erythrocyte membrane disturbance of OGG3P cationic polymer in the experiment concentrations from 0 to $60 \mu \mathrm{g} / \mathrm{mL}$, which was in favor of further biological applications. 


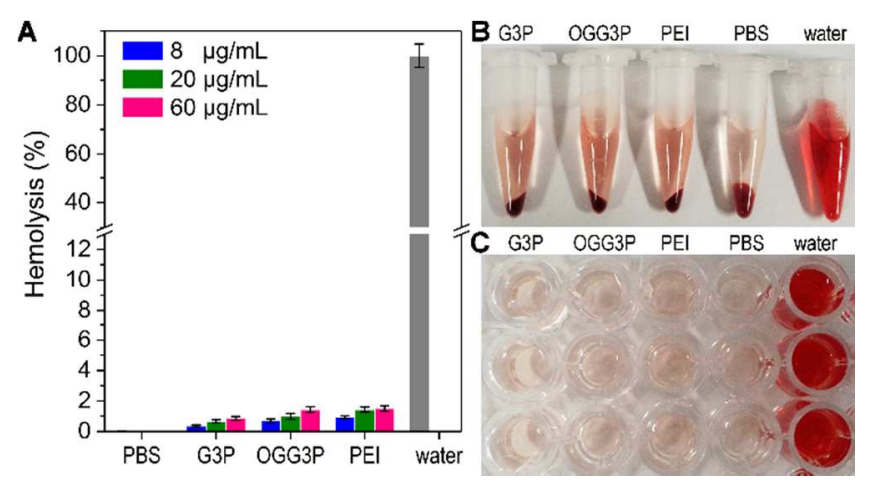

Figure 7. (A) Hemolytic activities towards mammalian red blood cells after treatment with cationic polymers (OGG3P, G3P, and PEI) at varying concentrations from 8 to $60 \mu \mathrm{g} / \mathrm{mL}$, using PBS buffer and water as negative and positive controls. (B) and (C) The cationic polymers were suspended at $60 \mu \mathrm{g} / \mathrm{mL}$. The solutions were followed by centrifugation to observe the presence of hemoglobin (red) in the supernatant visually.

In Vitro Gene Transfection. In general, cationic polymers can effectively form complexes with polyanionic nucleic acids via electrostatic attraction and serve as gene carriers to realize gene transfection. After complexation of the synthesized OGG3P or G3P cationic polymer with plasmid DNA, both complexes formed positively charged nanoparticles. The OGG3P complexes exhibited smaller size and narrower size distribution than that of G3P complexes. Hence, gene transfection experiments were performed to evaluate the superiority of the OGG3P cationic polymer for gene transfection in vitro and the optimal weight ratio of cationic polymer to DNA in both HEK293T and Hela cells. The green fluorescent protein expression level of the OGG3P complexes was much stronger than that offered by G3P complexes in both HEK293T (Figure 8A) 
and Hela (Figure 8B) cells in serum-free condition. The cationic polymer without guanidine modification, G3P, induced limited gene expression over the range of G3P to DNA weight ratios investigated in Hela cells. In contrast, different weight ratios of the octa-guanidine modified OGG3P cationic polymer to DNA in the range from 2 to 30 have successfully improved the transfection efficiency in both HEK293T and Hela cells. When the weight ratio of OGG3P to DNA was 10 in HEK293T cells in serum-free condition, OGG3P complexes achieved highest transfection efficiency.

To further validate the superiority of octa-guanidine modified OGG3P cationic polymer in gene transfection, gene transfection was also performed in serum-free medium or $10 \%$ serum conditions. The optimal ratio of cationic polymer to DNA for gene transfection and acceptable toxicity complexes was selected. In this study, the optimal weight ratio for OGG3P and G3P cationic polymer was observed to be a polymer:DNA ratio of 8 . Commercially available PEI with weight ratio at 1.33 , the optimal ratio for PEI, was served as a control. As indicated in Figure $8 \mathrm{C}$, octa-guanidine modified OGG3P was found to induce higher levels of green fluorescent protein expression than that of G3P in HEK293T cells in serum-free or 10\% serum conditions. Moreover, the octa-guanidine modified OGG3P retained a sufficient gene expression toward cultured HEK293T cells even in 10\% serum condition, which was sharply contrary to PEI showing a drastic decrease in the transfection efficiency under serum-containing conditions. Notably, OGG3P complexes mediated appreciable gene expression in a serum-free medium, which was much stronger than that of G3P or PEI complexes in the Hela cell line (Figure 8D). 
Serum-tolerable property of OGG3P cationic polymer in gene transfection was very different for these two cell lines. Only a few green fluorescent protein-positive cells can be detected in transfected Hela cells with OGG3P complexes under a serum-containing medium, whereas both G3P and PEI complexes induced no measurable green fluorescent protein expression.

\section{A HEK293T}
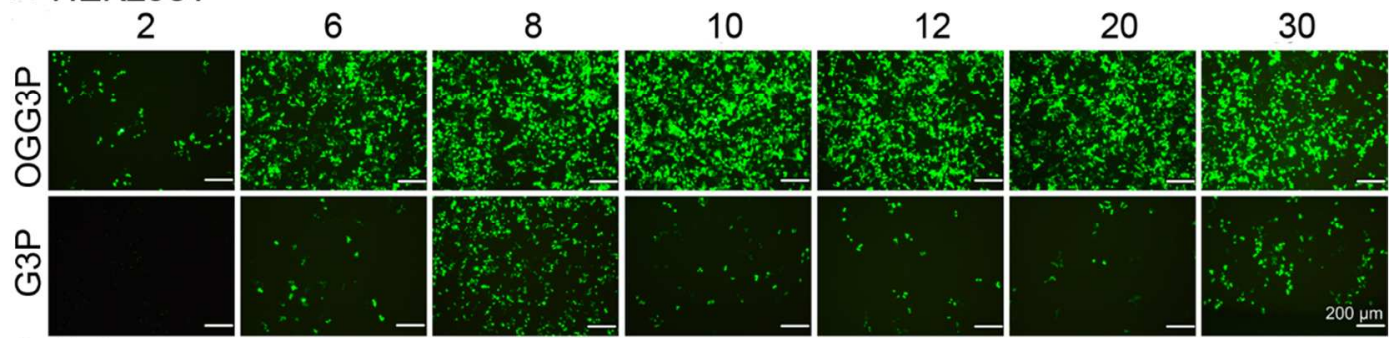

B Hela 2
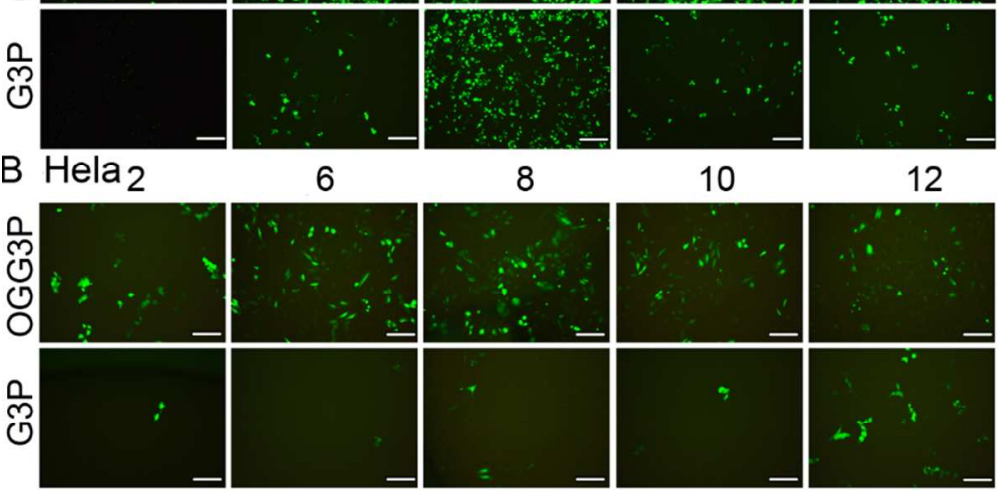

8

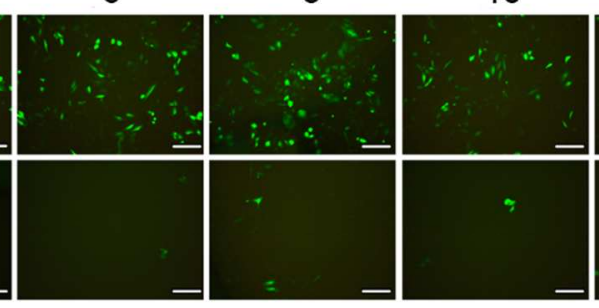

12
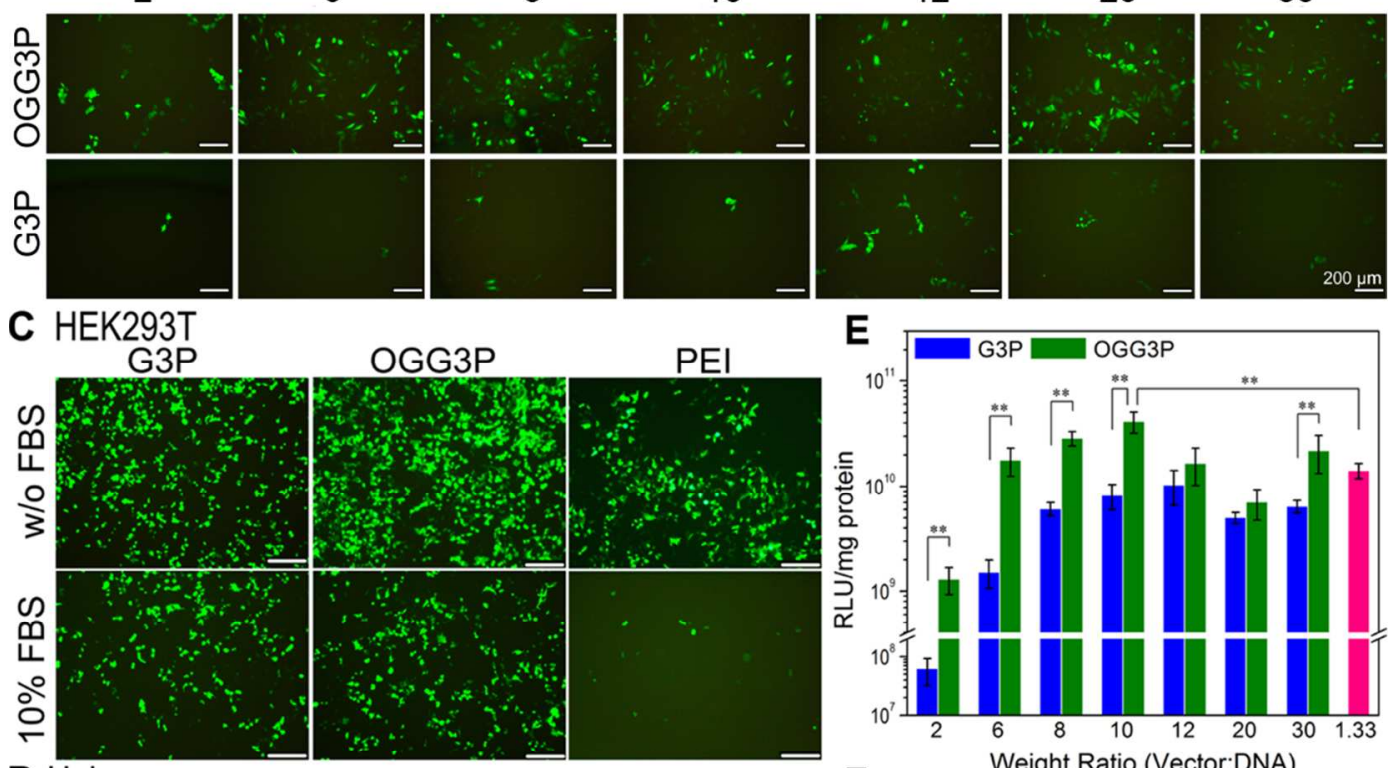

PEI

D Hela
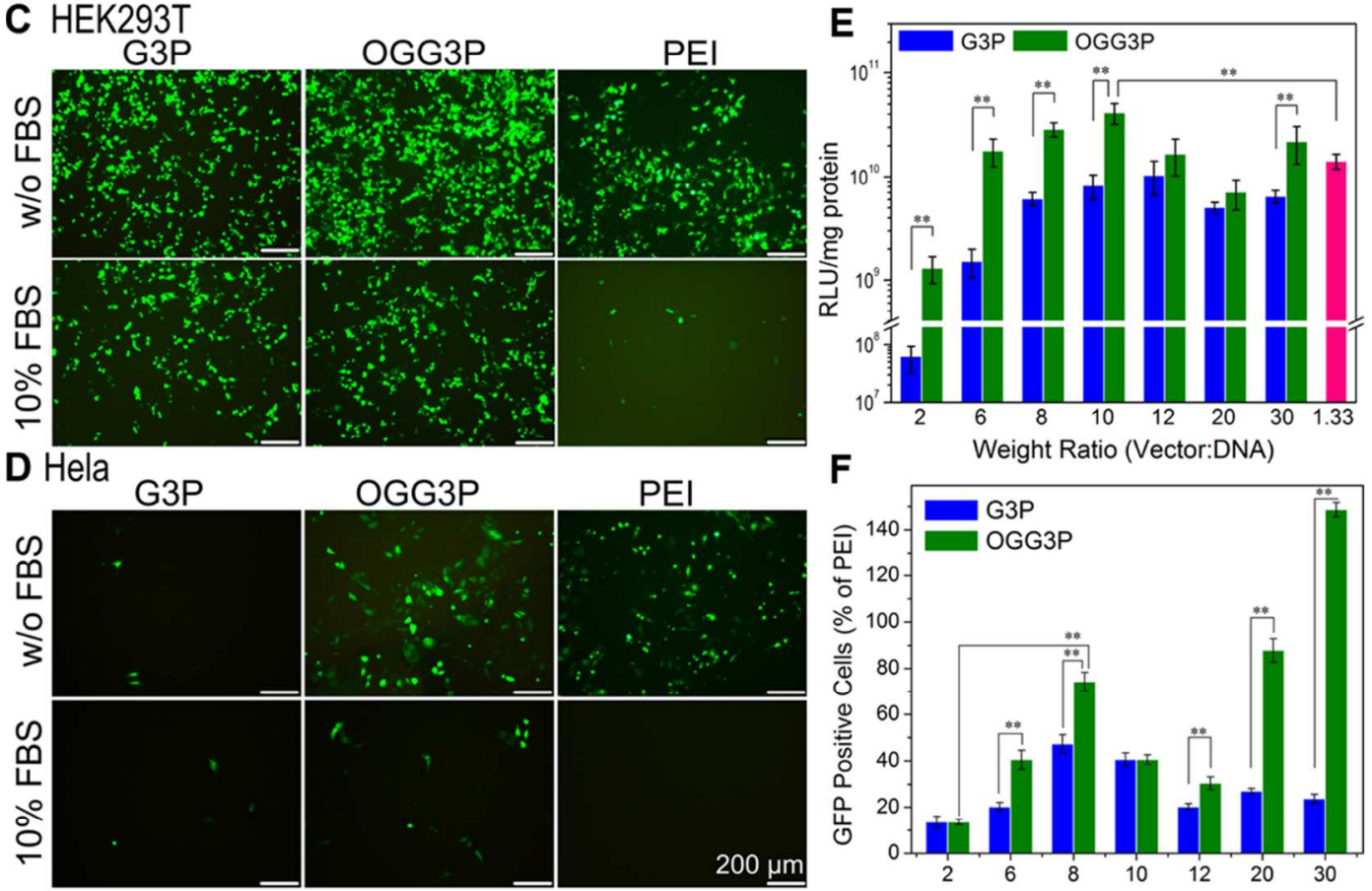

F

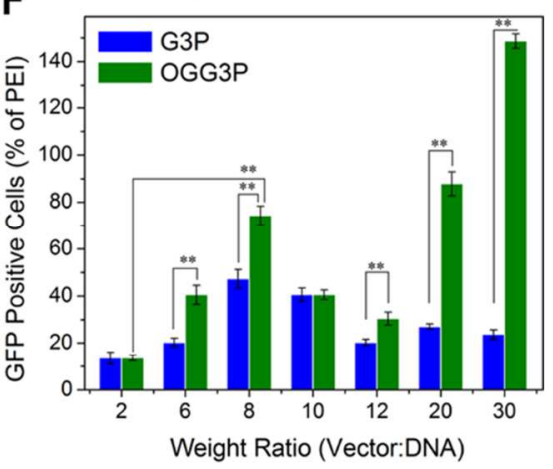

Figure 8. Gene transfection studies. EGFP transfection efficiency in (A) HEK293T and (B) Hela 
cells in the serum-free medium. EGFP transfection in (C) HEK293T and (D) Hela cells in the serum-free or serum-containing medium. (E) Luciferase activity of complexes in HEK293T cells in serum-free condition. (F) EGFP expressed in Hela cells transfected with different complexes in serum-free condition. $25 \mathrm{kD}$ PEI was served as a control. The data were determined by flow cytometry. $(\mathrm{n}=6, * * p<0.01)$.

Gene transfection efficiency in HEK293T cells was also quantified by using firefly luciferase plasmid. And the luciferase activity was normalized to total cell protein, which was determined by a BCA protein assay kit (Figure $8 \mathrm{E}$ ). With the increase of weight ratio of cationic polymer to DNA in both OGG3P and G3P complexes, the transfection efficiencies were progressively enhanced. However, there was little change in higher weight ratios from 12 to 30, which was supposed to result from severe cytotoxicity (Figure 6C). As a whole, much higher cationic polymer to DNA ratios were needed for optimal gene expression of OGG3P or G3P than that of PEI. It should be noted that higher gene expression was always achieved for the OGG3P complexes compared to the G3P complexes at the same weight ratio $(p<0.01)$. For instance, the luciferase assay indicated the luciferase expression of OGG3P complexes (cationic polymer to DNA weight ratio was 8) was up to 5-fold higher than G3P complexes and 3-fold greater than PEI complexes in HEK293T cells. This transfection efficiency enhancement of OGG3P cationic polymer presumably contributed by the octa-guanidine modification. ${ }^{24}$ The quantitative transfection results from Hela cells (Figure 8F) also demonstrated the superiority of 
octa-guanidine modified OGG3P as DNA nanocargoes to achieve an appreciable enhancement in gene transfection.

Intracellular Uptake Assay of Complexes. The transfection level of gene complexes is always associated with their cellular uptake patterns. To get insight into the mechanism of this significant effect of the octa-guanidine modification on the transfection efficacy, the cellular uptake pattern of OGG3P complexes was estimated in Hela cells using confocal laser scanning microscope (CLSM) and flow cytometry. As clearly shown in Figure 9A, the majority of the G3P and PEI complexes were widely distributed in the cytoplasm, while more red fluorescence emitting from OGG3P complexes was evenly distributed surrounding the cytoplasm region. In addition, the mean fluorescence intensities of OGG3P, G3P and PEI complexes internalized in the cytoplasm of Hela cells were also quantified. The histogram of flow cytometry (Figure 9B) revealed the relative mean fluorescence of Cy5-labeled DNA in the cell. It looked like OGG3P complexes had a little bit higher cellular uptake efficiencies as compared to that of G3P or PEI complexes. However, there was no significant difference. Although there was observed a significant enhancement of OGG3P complexes in the gene expression as compared with G3P or PEI complexes (Figure 8), the cellular uptake pattern of these complexes did not significantly influence the transfection efficiency (Figure 9A and 9B).

The OGG3P complexes with octa-guanidine modification exhibited excellent gene transfection, superior to the control of G3P complexes at similar cellular uptake efficiency. The results above urged us to raise a question whether the differences of the cellular uptake pathway 
resulted in enhancement of transfection between octa-guanidine modified OGG3P complexes and G3P complexes. There have been many literatures on the uptake mechanism of cell-penetrating peptides (CPP) including Tat sequences and arginine residues. ${ }^{34-35}$ It has been highlighted that CPP could improve cellular uptake and enter the cells mainly via macropinocytosis. As the literature reported, the arginine-rich peptide was mainly internalized by the macropinocytosis. ${ }^{36}$ However, the precise uptake mechanism of guanidine modified polymer based complexes is still under investigation. Therefore, we evaluated the cellular uptake pathway of OGG3P and G3P complexes in Hela cell line by pretreatment with several inhibitors including chlorpromazine, amiloride, and genistein. Chlorpromazine is a blocking agent in clathrin-mediated endocytosis. Genistein is famous for the inhibition of caveolae-mediated uptake process, and amiloride can block the $\mathrm{Na} / \mathrm{H}$ exchange required for macropinocytosis.

As Figure 9C shown, flow cytometry analysis represented the relative uptake efficiencies of OGG3P and G3P complexes after treated with different uptake inhibitors. Both genistein and chlorpromazine strongly inhibited the uptake efficiency of OGG3P and G3P complexes, indicating that caveolae-mediated and clathrin-mediated pathways are the major uptake pathways for these complexes. The uptake efficiency of the OGG3P complexes was reduced by $27 \%$ with amiloride pretreatment, whereas amiloride pretreatment did not affect the cellular uptake of G3P complexes, which indicated only OGG3P complexes could enter Hela cells through macropinocytosis pathway. These results demonstrated the evidence that the octa-guanidine modified OGG3P cationic polymer was uptaken in Hela cells via caveolae-mediated, 
clathrin-mediated and macropinocytosis pathways. For a better understanding of the cellular uptake pathway of G3P and OGG3P complexes, we proposed a model in Figure 9D.
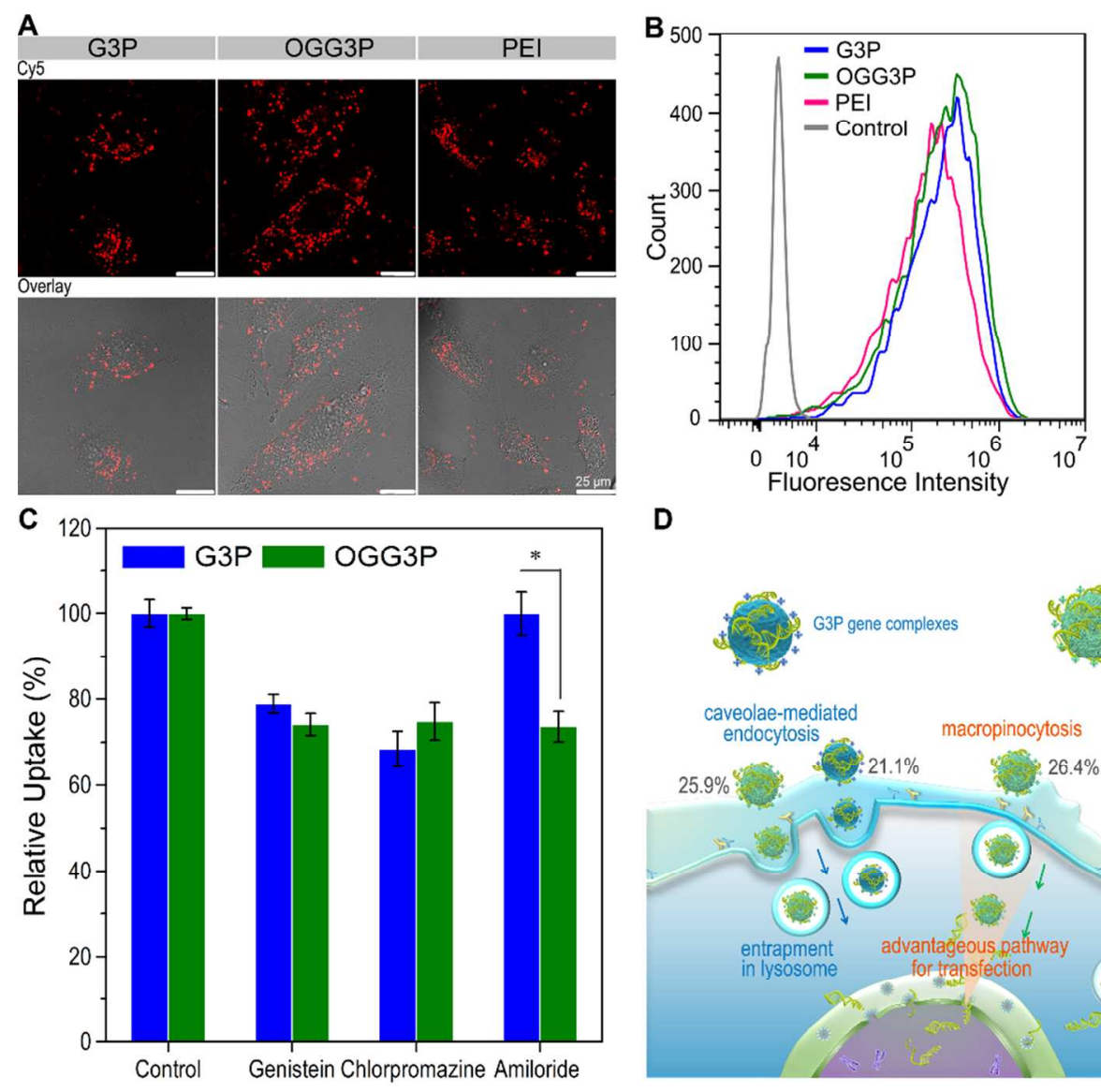

D
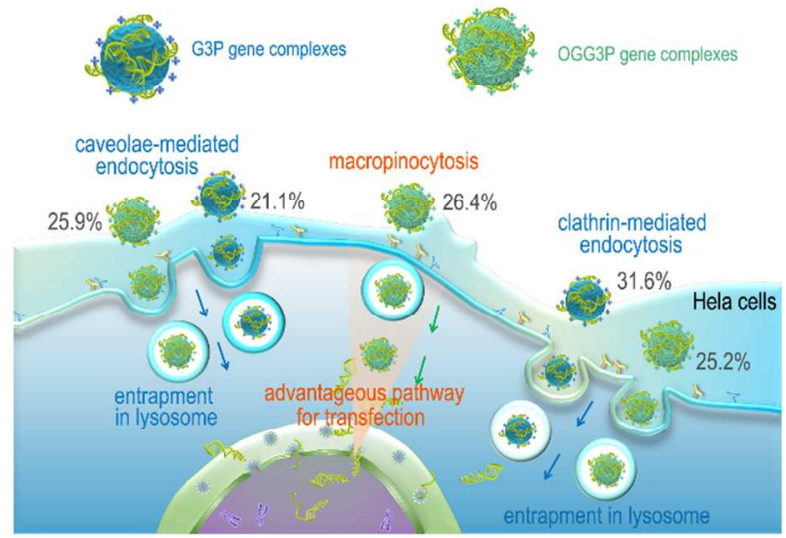

Figure 9. (A) Confocal laser scanning features of the cellular uptake of Cy5-labeled gene complexes in Hela cells after 7 hours incubation. (B) The cellular uptake of Cy5-labeled complexes in Hela cells at 7 hours' time point determined by flow cytometry. (C) Effects of different uptake inhibitors on the cellular uptake in Hela cells $\left(\mathrm{n}=3,{ }^{*} p<0.05\right)$. (D) Schematic illustration of the proposed uptake mechanism of OGG3P complexes and G3P complexes. G3P complexes are internalized by Hela cells via caveolae-mediated pathway (21.1\%), clathrin-mediated pathway (31.6\%), and other pathways (47.3\%). While OGG3P complexes are 
internalized by Hela cells via macropinocytosis (26.4\%), caveolae-mediated pathway (25.9\%), and clathrin-mediated pathway (25.2\%), as well as other pathways $(22.5 \%)$.

Taken all together, there was no remarkable difference in uptake efficiency between OGG3P and G3P complexes despite their structural differences. In other words, octa-guanidine modification did not have any significant functions on cellular uptake of OGG3P complexes. However, it may contribute to cellular uptake pathways and lead to macropinocytosis pathway. Considering this fact, it could be concluded that the significantly enhanced transfection efficiency of OGG3P was not resulted from its cellular uptake capacity but mediation by macropinocytosis uptake pathway, which may endow OGG3P complexes a stronger ability to facilitate endosomal escape than that of G3P complexes. ${ }^{37-39}$

Photoactivation of KillerRed, ROS Production, and Cell Proliferation. Above results could illustrate why the OGG3P complexes achieved better performance than G3P complexes in the transfection efficiency even at a similar cellular uptake level but with different uptake pathway. For further investigate the therapeutic gene transfection by the OGG3P cationic polymer, pKillerRed-mem was employed and formulated with the OGG3P cationic polymer to form OGG3P complexes. Photosensitizer KillerRed is a genetically encoded red fluorescent protein that holds promise as a candidate for the widely applied hydrophobic photosensitizers in clinical photodynamic therapy (PDT). KillerRed protein can encounter photoactivation and produce ROS once exposed to the green light irradiation, facilitating light-induced cell 
destructions at molecular levels for killing cells and cancer therapy. The maximum excitation and emission wavelength of KillerRed are 585 and $610 \mathrm{~nm}$, respectively. In Hela cells transfected with the OGG3P complexes, upon green light irradiation, the KillerRed photoactivation mediated ROS production was visually investigated using DCFH-DA green reagent as a fluorogenic probe and observed through the fluorescence microscope. As Figure 10A shown, there was no green fluorescence signal of ROS in Hela cells detected before irradiation, indicating the production of ROS depended on the KillerRed photoactivation upon green light irradiation. Moreover, as the light irradiation duration grew, the green fluorescence intensity of ROS also enhanced noticeably and reached a platform at 2 min, implying that the production of ROS was activated by green light irradiation and achieved the maximum when the light irradiation time was 2 min. In addition, the quantitative determination of the ROS generation after different light exposure was also carried out, suggesting the irradiation time for the optimal ROS production was 2 min in Figure 10B. More importantly, the green fluorescence of produced ROS could co-locate well with the blue signals of nuclei and the red fluorescence of KillerRed protein, leading to nuclear damages after 2 min irradiation. Following by irradiation, the KillerRed expression cells also displayed morphologic change, such as rounded shape and shrinkage (Figure 10C). 
A

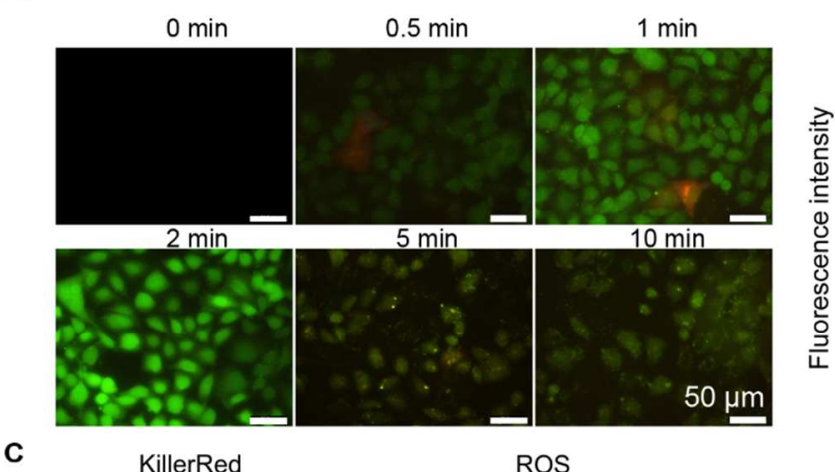

C

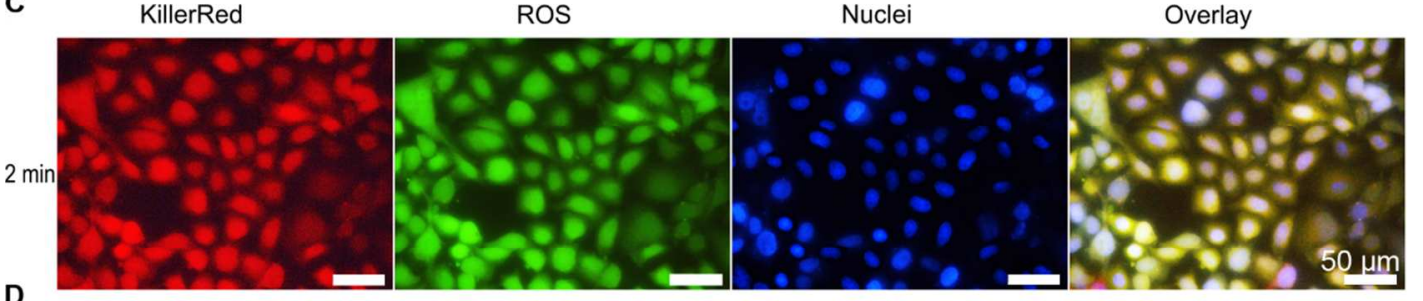

D

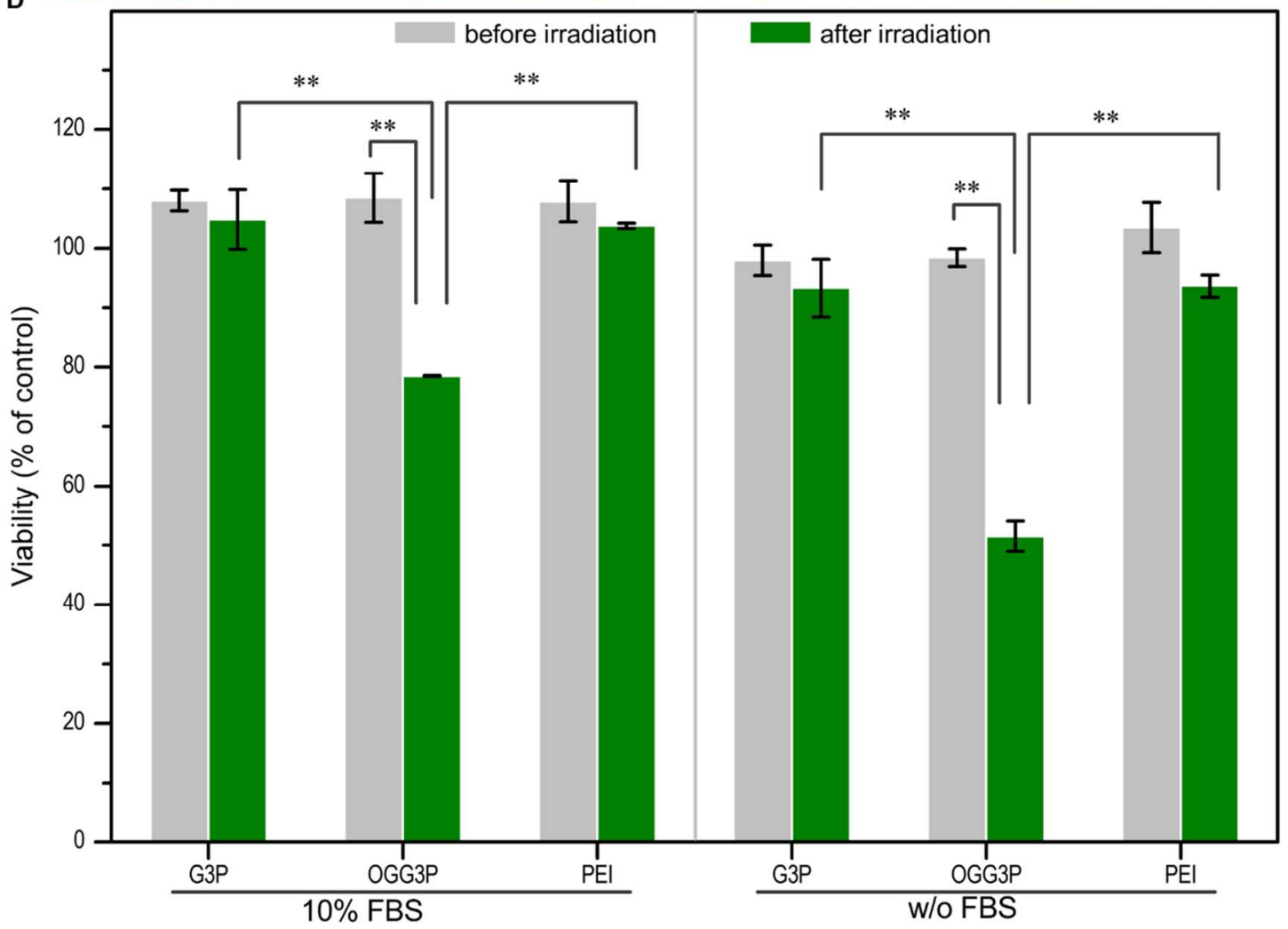

Figure 10. KillerRed-mediated ROS production in Hela cells transfected with OGG3P complexes after light irradiation for different durations, in which the DCFH-DA green fluorescent probe identified ROS (532 nm, $4 \mathrm{~W} / \mathrm{cm}^{2}$ ). (A) Confocal images showed ROS production. (B) The 
fluorescence intensity of the ROS generation was quantified by flow cytometry. (C) Confocal microscopy features illustrating KillerRed expression and ROS production mediated by KillerRed photoactivation in transfected Hela cells after 2 min irradiation, in which DCFH-DA and DAPI identified ROS and nuclei. (D) The photocytotoxicity of pKillerRed-mem formulated complexes transfected Hela cells with or without green light for $2 \mathrm{~min}$. All of the complexes were formulated at their respective optimal weight ratios. $(\mathrm{n}=6, * * P<0.01)$

The observation of KillerRed-mediated ROS production in Hela cells upon light irradiation prompted us to investigate the inhibitory influence of photodynamic therapy on the KillerRed-expressed cells. Therefore, the cellular proliferation of OGG3P complexes in transfected Hela cells was evaluated by the CCK-8 kit with or without light irradiation. Figure $10 \mathrm{D}$ clearly indicated that all DNA complexes never displayed any measurable proliferation reduction in Hela cells before light exposure in 10\% serum or serum-free condition. Notably, 2 min after exposure, transfection with OGG3P complexes could lead to $36 \%$ and $53 \%$ activity reduction in comparison with the unirradiated control group in $10 \%$ serum or serum-free condition, respectively, whereas both G3P complexes and PEI complexes only induced a slight reduction in proliferation of Hela cells after light exposure. These results illustrated the guanidinylated pullulan derivative (OGG3P) could work as a useful platform for the genetic photodynamic therapy of tumor. 


\section{CONCLUSIONS}

In summary, we have developed a tailor-made guanidine-decorated dendronized pullulan, octa-guanidine functionalized generation 3 lysine dendrons-graft-pullulan (OGG3P), to engineer vectors for genetic photodynamic therapy. The obtained OGG3P is efficient in compressing DNA into spherical nanosized complexes with appropriate positive surface charges to enable entry into cells and to assure successful gene delivery. OGG3P possessed excellent hemocompatibility without obvious hemolysis. It also demonstrated cell-dependent cytotoxicity in comparison with PEI and G3P. Interestingly, the OGG3P with octa-guanidine modification exhibited much higher gene transfection in Hela and HEK293T cells, superior to the control of G3P lacking guanidine residues at the similar cellular uptake efficiency. By combining the uptake pathway results, we found that guanidine modification did not facilitate the cellular uptake of OGG3P complexes but cause the changes in uptake pathway and lead to macropinocytosis pathway. The macropinocytosis pathway of OGG3P may be a crucial reason for the improved transfection efficiency. Additionally, the introduction of a therapeutic plasmid, pKillerRed-mem, also showed the prospects of curing the tumor. Intercellular activation of KillerRed via the vectors gave rise to the production of ROS and obvious cytotoxicity. We believe that this guanidine-decorated dendronized pullulan could serve as a reliable gene delivery nanoplatform to enable delivery of therapeutic genes. 


\section{AUTHOR INFORMATION}

\section{Corresponding Author}

*E-mail: heyiyan2005@163.com.

*E-mail: zwgu1006@hotmail.com.

\section{ORCID}

Yiyan He: 0000-0002-1568-6047

Zhongwei Gu: 0000-0003-1547-6880

\section{Notes}

The authors declare no competing financial interest.

\section{ACKNOWLEDGEMENTS}

This work was financially supported by National Natural Science Foundation of China (No. 81361140343, 31500810, 81621003, and 31771067), the National Key Research and Development Program of China (2017YFC1103500, 2017YFC1103501), International Science and Technology Cooperation Program of China (2015DFE52780), and the European Union's Seventh Framework Programme (PIRSES-GA-2011-295218).

\section{REFERENCES}

(1) Yin, H.; Kanasty, R. L.; Eltoukhy, A. A.; Vegas, A. J.; Dorkin, J. R.; Anderson, D. G. 
Non-viral vectors for gene-based therapy. Nat. Rev. Genet. 2014, 15 (8), 541-55.

(2) Shi, B.; Zheng, M.; Tao, W.; Chung, R.; Jin, D.; Ghaffari, D.; Farokhzad, O. C. Challenges in DNA Delivery and Recent Advances in Multifunctional Polymeric DNA Delivery Systems. Biomacromolecules 2017, 18 (8), 2231-2246.

(3) He, Y.; Nie, Y.; Cheng, G.; Xie, L.; Shen, Y.; Gu, Z. Viral Mimicking Ternary Polyplexes: A Reduction - Controlled Hierarchical Unpacking Vector for Gene Delivery. Adv. Mater. 2014, 26 (10), 1534-1540.

(4) Liu, S.; Zhou, D.; Yang, J.; Zhou, H.; Chen, J.; Guo, T. Bioreducible Zinc(II)-Coordinative Polyethylenimine with Low Molecular Weight for Robust Gene Delivery of Primary and Stem Cells. J. Am. Chem. Soc. 2017, 139 (14), 5102-5109.

(5) He, Y.; Cheng, G.; Xie, L.; Nie, Y.; He, B.; Gu, Z. Polyethyleneimine/DNA polyplexes with reduction-sensitive hyaluronic acid derivatives shielding for targeted gene delivery. Biomaterials 2013, 34, 1235-1245.

(6)Lim, D. G.; Rajasekaran, N.; Lee, D.; Kim, N. A.; Jung, H. S.; Hong, S.; Shin, Y. K.; Kang, E.; Jeong, S. H. Polyamidoamine-Decorated Nanodiamonds as a Hybrid Gene Delivery Vector and siRNA Structural Characterization at the Charged Interfaces. ACS Appl. Mater. Interfaces 2017, 9 (37), 31543-31556.

(7) Reyes-Reveles, J.; Sedaghat-Herati, R.; Gilley, D. R.; Schaeffer, A. M.; Ghosh, K. C.; Greene, T. D.; Gann, H. E.; Dowler, W. A.; Kramer, S.; Dean, J. M.; Delong, R. K. mPEG-PAMAM-G4 Nucleic Acid Nanocomplexes: Enhanced Stability, RNase Protection, and Activity of Splice Switching Oligomer and Poly I:C RNA. Biomacromolecules 2013, 14 (11), 4108-4115.

(8) Sheikh, M. A.; Malik, Y. S.; Xing, Z.; Guo, Z.; Tian, H.; Zhu, X.; Chen, X. Polylysine-modified polyethylenimine (PEI-PLL) mediated VEGF gene delivery protects dopaminergic neurons in cell culture and in rat models of Parkinson's Disease (PD). Acta Biomater. 2017, 54, 58-68.

(9) Nel, A. E.; Mädler, L.; Velegol, D.; Xia, T.; Hoek, E. M. V.; Somasundaran, P.; Klaessig, F.; Castranova, V.; Thompson, M. Understanding biophysicochemical interactions at the nano-bio interface. Nat. Mater. 2009, 8, 543.

(10) O’Keeffe Ahern, J.; A, S.; Zhou, D.; Gao, Y.; Lyu, J.; Meng, Z.; Cutlar, L.; Pierucci, L.; Wang, W. Brushlike Cationic Polymers with Low Charge Density for Gene Delivery. Biomacromolecules 2017.

(11) Albuquerque, L. J. C.; de Castro, C. E.; Riske, K. A.; da Silva, M. C. C.; Muraro, P. I. R.; Schmidt, V.; Giacomelli, C.; Giacomelli, F. C. Gene Transfection Mediated by Catiomers Requires Free Highly Charged Polymer Chains To Overcome Intracellular Barriers. Biomacromolecules 2017, 18 (6), 1918-1927.

(12) Suk, J. S.; Xu, Q.; Kim, N.; Hanes, J.; Ensign, L. M. PEGylation as a strategy for improving nanoparticle-based drug and gene delivery. Adv. Drug Delivery Rev. 2016, 99, 28-51.

(13) Yang, X.-C.; Niu, Y.-L.; Zhao, N.-N.; Mao, C.; Xu, F.-J. A biocleavable 
pullulan-based vector via ATRP for liver cell-targeting gene delivery. Biomaterials 2014, 35 (12), 3873-3884.

(14) Singh, R. S.; Kaur, N.; Kennedy, J. F. Pullulan and pullulan derivatives as promising biomolecules for drug and gene targeting. Carbohydr. Polym. 2015, 123, 190-207.

(15) Luo, K.; He, B.; Wu, Y.; Shen, Y.; Gu, Z. Functional and biodegradable dendritic macromolecules with controlled architectures as nontoxic and efficient nanoscale gene vectors. Biotechnol. Adv. 2014, 32 (4), 818-830.

(16) Luo, K.; Li, C.; Wang, G.; Nie, Y.; He, B.; Wu, Y.; Gu, Z. Peptide dendrimers as efficient and biocompatible gene delivery vectors: Synthesis and in vitro characterization. $J$. Control. Release 2011, 155 (1), 77-87.

(17) Xu, X.; Jian, Y.; Li, Y.; Zhang, X.; Tu, Z.; Gu, Z. Bio-Inspired Supramolecular Hybrid Dendrimers Self-Assembled from Low-Generation Peptide Dendrons for Highly Efficient Gene Delivery and Biological Tracking. ACS Nano 2014, 8 (9), 9255-9264.

(18) Xu, X.; Yuan, H.; Chang, J.; He, B.; Gu, Z. Cooperative Hierarchical Self-Assembly of Peptide Dendrimers and Linear Polypeptides into Nanoarchitectures Mimicking Viral Capsids. Angew. Chem., Int. Ed. 2012, 124 (13), 3184-3187.

(19) Wang, M.; Liu, H.; Li, L.; Cheng, Y. A fluorinated dendrimer achieves excellent gene transfection efficacy at extremely low nitrogen to phosphorus ratios. Nat. Commun. 2014, 5, 3053.

(20) Chang, H.; Zhang, J.; Wang, H.; Lv, J.; Cheng, Y. A Combination of Guanidyl and Phenyl Groups on a Dendrimer Enables Efficient siRNA and DNA Delivery. Biomacromolecules 2017, 18 (8), 2371-2378.

(21) Nakase, I.; Takeuchi, T.; Tanaka, G.; Futaki, S. Methodological and cellular aspects that govern the internalization mechanisms of arginine-rich cell-penetrating peptides. Adv. Drug Delivery Rev. 2008, 60 (4-5), 598-607.

(22) Veiman, K. L.; Kunnapuu, K.; Lehto, T.; Kiisholts, K.; Parn, K.; Langel, U.; Kurrikoff, K. PEG shielded MMP sensitive CPPs for efficient and tumor specific gene delivery in vivo. J Control Release 2015, 209, 238-47.

(23) Kim, T. I.; Ou, M.; Lee, M.; Kim, S. W. Arginine-grafted bioreducible poly(disulfide amine) for gene delivery systems. Biomaterials 2009, 30 (4), 658-64.

(24) Kim, T. I.; Lee, M.; Kim, S. W. A guanidinylated bioreducible polymer with high nuclear localization ability for gene delivery systems. Biomaterials 2010, 31 (7), 1798-804.

(25) Choi, J.-y.; Ryu, K.; Lee, G. J.; Kim, K.; Kim, T.-i. Agmatine-Containing Bioreducible Polymer for Gene Delivery Systems and Its Dual Degradation Behavior. Biomacromolecules 2015, 16 (9), 2715-2725.

(26) Tseng, S. J.; Liao, Z.-X.; Kao, S.-H.; Zeng, Y.-F.; Huang, K.-Y.; Li, H.-J.; Yang, C.-L.; Deng, Y.-F.; Huang, C.-F.; Yang, S.-C.; Yang, P.-C.; Kempson, I. M. Highly specific in vivo gene delivery for p53-mediated apoptosis and genetic photodynamic therapies of tumour. Nat. Commun. 2015, $6,6456$.

(27) Liao, Z.-X.; Li, Y.-C.; Lu, H.-M.; Sung, H.-W. A genetically-encoded KillerRed 
protein as an intrinsically generated photosensitizer for photodynamic therapy. Biomaterials 2014, 35 (1), 500-508.

(28) Li, H.; Xu, X.; Li, Y.; Geng, Y.; He, B.; Gu, Z. Design and self-assembly of amphiphilic peptide dendron-jacketed polysaccharide polymers into available nanomaterials. Polym. Chem. 2013, 4 (7), 2235-2238.

(29) Cimecioglu, A. L.; Ball, D. H.; Huang, S. H.; Kaplan, D. L. A Direct Regioselective Route to 6-Azido-6-deoxy Polysaccharides under Mild and Homogeneous Conditions. Macromolecules 1997, 30 (1), 155-156.

(30) Bulina, M. E.; Chudakov, D. M.; Britanova, O. V.; Yanushevich, Y. G.; Staroverov, D. B.; Chepurnykh, T. V.; Merzlyak, E. M.; Shkrob, M. A.; Lukyanov, S.; Lukyanov, K. A. A genetically encoded photosensitizer. Nat. Biotechnol. 2006, 24 (1), 95-9.

(31) Michael S. Bernatowicz, Y. W., and Gary R. Matsueda 1H-Pyrazole-1-carboxamidine Hydrochloride: An Attractive Reagent for Guanylation of Amines and Its Application to Peptide Synthesis. J. Org. Chem. 1992, 57 (8), 2497-2502.

(32) Fischer, D.; Li, Y.; Ahlemeyer, B.; Krieglstein, J.; Kissel, T. In vitro cytotoxicity testing of polycations: influence of polymer structure on cell viability and hemolysis. Biomaterials 2003, 24 (7), 1121-1131.

(33) Philip, R.; Campbell, E.; Wheatley, D. N. Arginine deprivation, growth inhibition and tumour cell death: 2. Enzymatic degradation of arginine in normal and malignant cell cultures. Br. J. Cancer 2003, 88, 613.

(34) Tang, H.; Yin, L.; Kim, K. H.; Cheng, J. Helical Poly(arginine) Mimics with Superior Cell-Penetrating and Molecular Transporting Properties. Chem. Sci. 2013, 4 (10), 3839-3844.

(35) Futaki, S. Oligoarginine vectors for intracellular delivery: design and cellular-uptake mechanisms. Biopolymers 2006, 84 (3), 241-9.

(36) Tae-il Kim, J.-u. B., † Jae Keun Yoon, $\uparrow$ Joon Sig Choi, $\uparrow$ Kwan Kim, $\uparrow$ and Jong-sang Park $^{*}, \uparrow$. Synthesis and Characterization of a Novel Arginine-Grafted Dendritic Block

Copolymer for Gene Delivery and Study of Its Cellular Uptake Pathway Leading

to Transfection. Bioconjugate Chem. 2007, 18 (2), 309-317.

(37) El-Sayed, A.; Khalil, I. A.; Kogure, K.; Futaki, S.; Harashima, H. Octaarginine- and octalysine-modified nanoparticles have different modes of endosomal escape. J. Biol. Chem. 2008, 283 (34), 23450-61.

(38) Omata, D.; Negishi, Y.; Hagiwara, S.; Yamamura, S.; Endo-Takahashi, Y.; Suzuki, R.; Maruyama, K.; Nomizu, M.; Aramaki, Y. Bubble liposomes and ultrasound promoted endosomal escape of TAT-PEG liposomes as gene delivery carriers. Mol. Pharm. 2011, 8 (6), 2416-23.

(39) Yamada, Y.; Hashida, M.; Harashima, H. Hyaluronic acid controls the uptake pathway and intracellular trafficking of an octaarginine-modified gene vector in CD44 positiveand CD44 negative-cells. Biomaterials 2015, 52, 189-98. 
Table of Contents Graphic $(3.6 \times 8.9 \mathrm{~cm})$

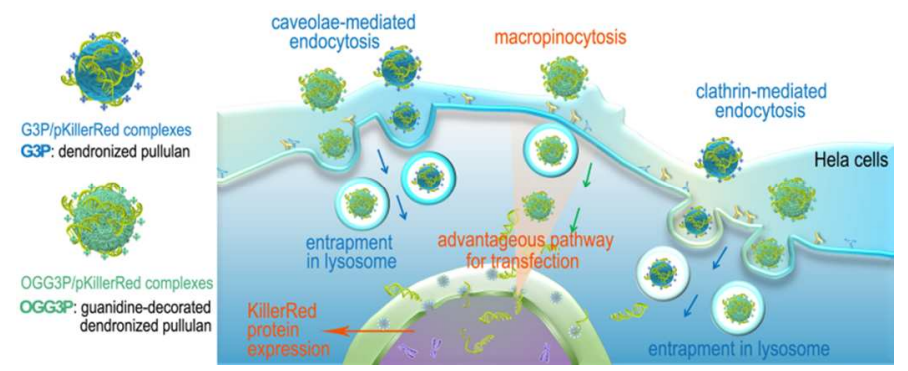

ACS Paragon Plus Environment 